The University of Southern Mississippi

The Aquila Digital Community

Master's Theses

Summer 2019

\title{
Emotion Reactivity, Emotion Dysregulation, and Non-Suicidal Self- Injury among At-Risk Adolescents: A Multiple Mediation Analysis
}

Paula N. Floyd

University of Southern Mississippi

Follow this and additional works at: https://aquila.usm.edu/masters_theses

Part of the Clinical Psychology Commons

\section{Recommended Citation}

Floyd, Paula N., "Emotion Reactivity, Emotion Dysregulation, and Non-Suicidal Self-Injury among At-Risk Adolescents: A Multiple Mediation Analysis" (2019). Master's Theses. 654.

https://aquila.usm.edu/masters_theses/654

This Masters Thesis is brought to you for free and open access by The Aquila Digital Community. It has been accepted for inclusion in Master's Theses by an authorized administrator of The Aquila Digital Community. For more information, please contact Joshua.Cromwell@usm.edu. 


\title{
EMOTION REACTIVITY, EMOTION DYSREGULATION, AND \\ NON-SUICIDAL SELF-INJURY AMONG AT-RISK ADOLESCENTS: \\ A MULTIPLE MEDIATION ANALYSIS
}

by

Paula N. Floyd

\begin{abstract}
A Thesis
Submitted to the Graduate School, the College of Education and Human Sciences and the School of Psychology

at The University of Southern Mississippi

in Partial Fulfillment of the Requirements

for the Degree of Master of Arts
\end{abstract}

Approved by:

Nora Charles, Committee Chair

Mike Anestis

Ashley Batastini

Dr. Nora Charles

Committee Chair
Dr. D. Joe Olmi

Director of School
Dr. Karen S. Coats

Dean of the Graduate School 


\section{COPYRIGHT BY}

Paula N. Floyd

2019

Published by the Graduate School

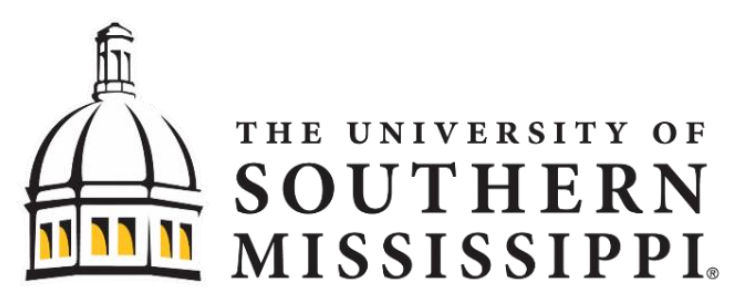




\begin{abstract}
Non-suicidal self-injury (NSSI) is defined as deliberate self-inflicted damage to bodily tissue without the intent to die. NSSI has been identified as a major health concern, as it is related to both poor psychosocial outcomes and increased suicide risk. NSSI is especially important to understand among adolescents, as age of onset is typically during adolescence and prevalence rates are highest among this age group. One of the most well-established correlates of NSSI is emotion dysregulation. While many studies have examined emotion dysregulation and its subcomponents in relation to selfinjury, there has been far less work devoted to factors that may increase one's likelihood of being emotionally dysregulated. Previous literature suggests that emotion dysregulation is strongly influenced by individual levels of emotion reactivity; however, no studies to date have assessed the combined effects of emotion reactivity and emotion dysregulation in terms of NSSI frequency. In addition, prior research suggests that the cognitive process of rumination may play a role in NSSI engagement. The current study sought to understand the relationships between emotion reactivity, distinct facets of emotion dysregulation, rumination, and NSSI among a sample of at-risk youth in a residential facility. Furthermore, a multiple mediation model was used to test which facets of emotion dysregulation serve as the most powerful mediators between emotion reactivity and NSSI frequency. Findings and implications are discussed.
\end{abstract}




\section{ACKNOWLEDGMENTS}

First and foremost, I would like to express a sincere appreciation for my committee chair and major professor, Dr. Nora Charles. My interest in and knowledge about the research process has grown tremendously under your guidance. Not only has Dr. Charles consistently provided me with the support needed to complete this project, but she has also challenged me to think more critically about how to approach my work.

I also wish to thank my thesis committee members, Dr. Michael Anestis and Dr. Ashley Batastini, for devoting their time to my thesis project. They offered invaluable feedback and insight that I will carry with me in future research endeavors.

Next, I am grateful to all of the graduate students and research assistants who assisted with data collection for my thesis. I feel very fortunate to be surrounded by so many bright, hard-working, and collaborative individuals. 


\section{DEDICATION}

This thesis project is dedicated to my parents, Robert and Myra, who serve as my constant inspiration to succeed. 


\section{TABLE OF CONTENTS}

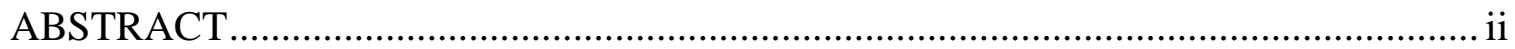

ACKNOWLEDGMENTS .............................................................................. ii

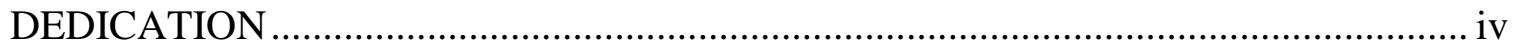

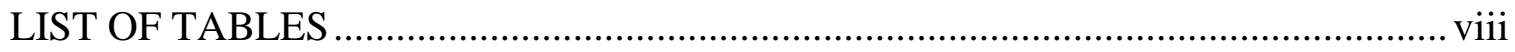

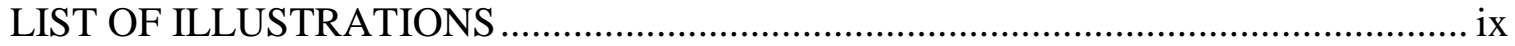

LIST OF ABBREVIATIONS ...........................................................................

CHAPTER I - INTRODUCTION .................................................................... 1

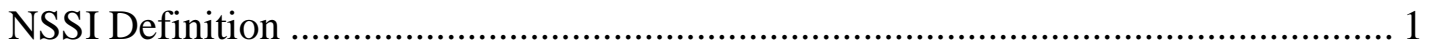

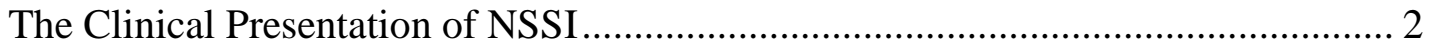

Theories of the Development of NSSI................................................................... 3

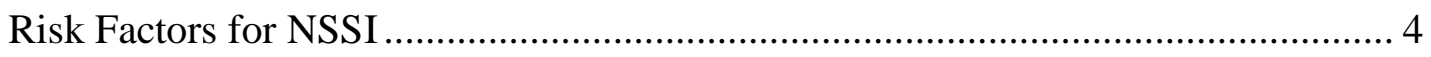

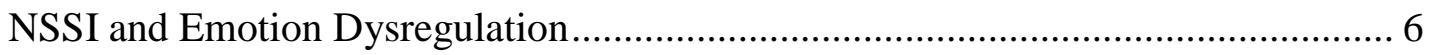

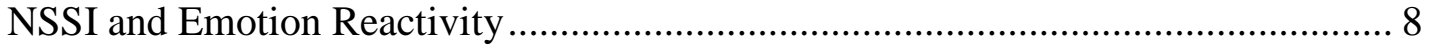

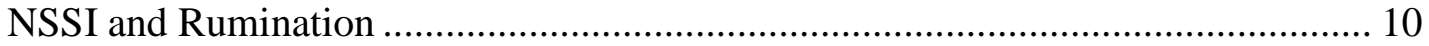

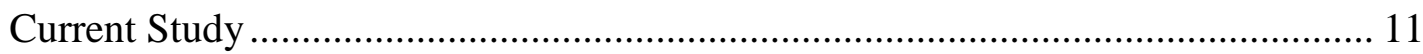

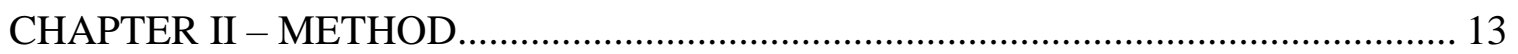

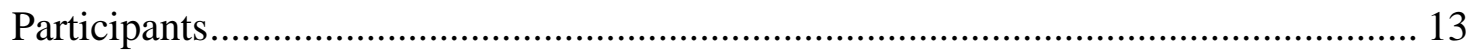

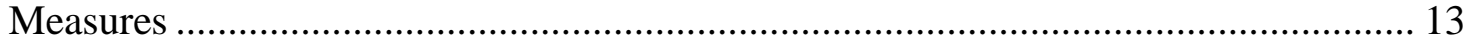

Demographic Factors ............................................................................... 13 
Emotional Reactivity

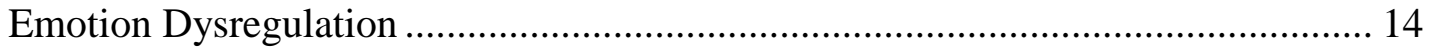

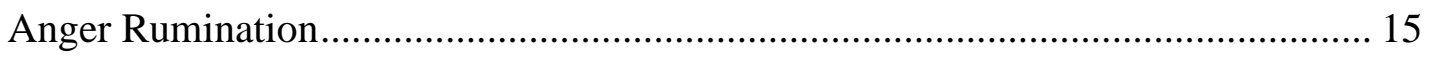

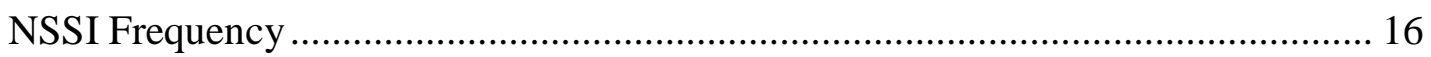

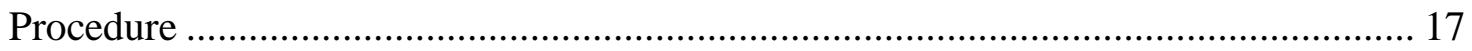

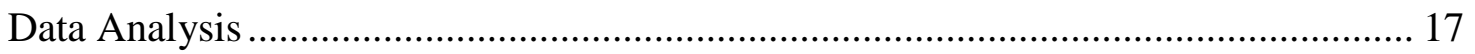

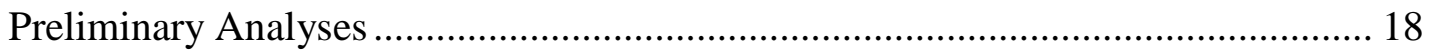

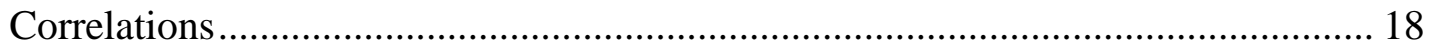

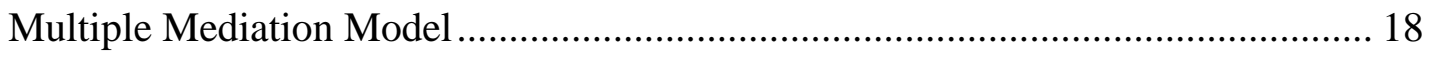

CHAPTER III - RESULTS............................................................................... 21

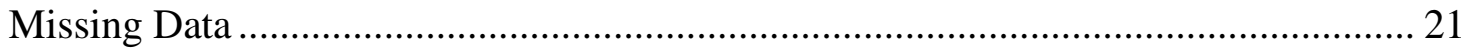

Demographic Comparisons......................................................................... 21

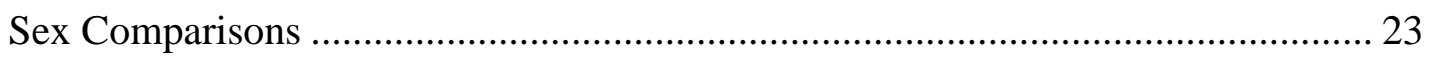

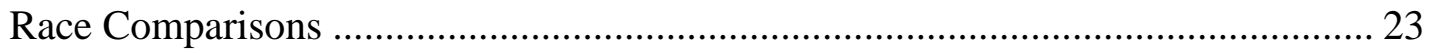

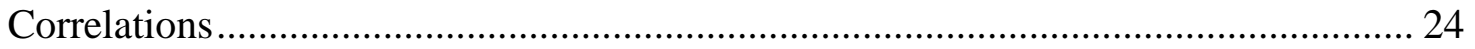

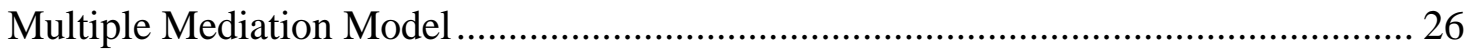

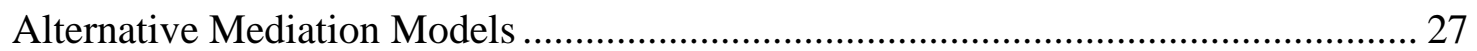

Alternative Moderation Model .............................................................................. 27

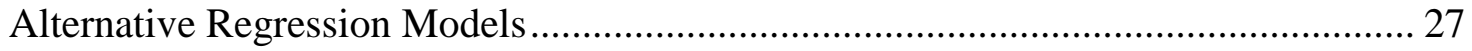

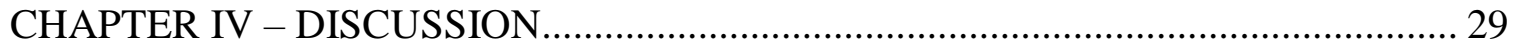


Strengths and Limitations

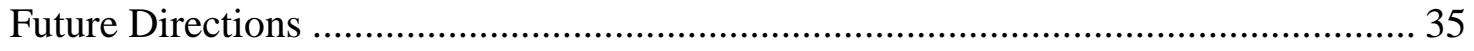

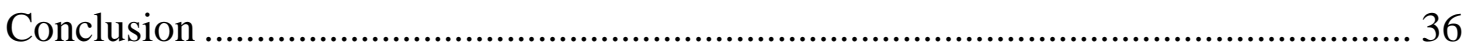

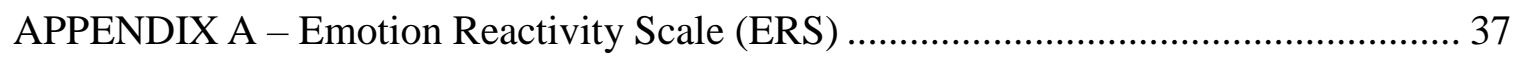

APPENDIX B - Difficulties in Emotion Regulation Scale (DERS) ............................. 38

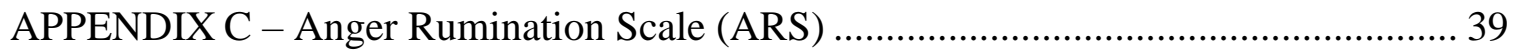

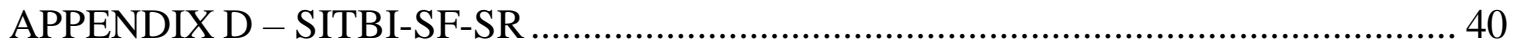

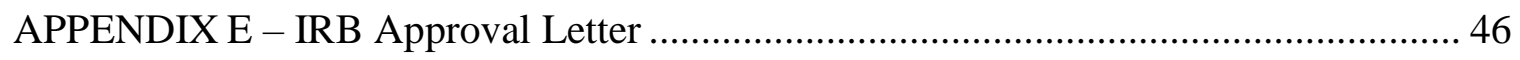

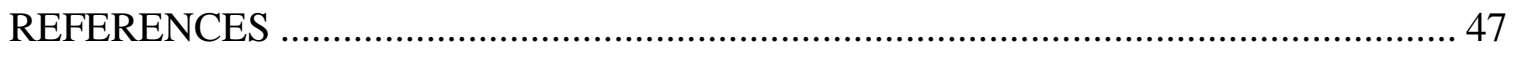




\section{LIST OF TABLES}

Table 1 Demographic comparisons

Table 2 Correlations between IVs and NSSI frequency....

Table 3 Correlations between independent variables ................................................... 25

Table 4 DERS subscales as predictors of NSSI frequency ...................................... 28

Table 5 DERS and ARS as predictors of NSSI frequency ........................................ 28 


\section{LIST OF ILLUSTRATIONS}

Figure 1. Proposed multiple mediation model ............................................................ 19

Figure 2. Multiple mediation model results ................................................................. 26 


\section{LIST OF ABBREVIATIONS}

NSSI

DERS

ERS

ARS
Non-suicidal self-injury

Difficulties in Emotion Regulation Scale

Emotion Reactivity Scale

Anger Rumination Scale 


\section{CHAPTER I - INTRODUCTION}

Non-suicidal self-injury (NSSI) is defined as deliberate self-inflicted damage to bodily tissue without the intent to die (Nock \& Favazza, 2009; Klonsky \& Olino, 2008). Common NSSI methods include cutting, severe scratching, biting, hair pulling, and carving into the skin, with cutting being most frequently endorsed across various populations (Glenn \& Klonsky, 2011; Klonsky, 2011; Sornberger, Heath, Toste, \& McLouth, 2012; Anestis, Khazem, \& Law, 2015). NSSI is considered a major public health concern, as it has been linked to a number of poor outcomes and places individuals at increased risk for suicide-related behavior (Nock, Joiner, Gordon, Lloyd-Richardson, \& Prinstein, 2006). The average reported age of onset for NSSI is in early to midadolescence (Jacobson \& Gould, 2007; Klonsky, 2007; Nixon, Cloutier, \& Jansson, 2008; Andrews, Martin, Hasking, \& Page, 2014) and recent reviews have indicated that NSSI prevalence rates among community-based samples of adolescents typically range from 13.0\% to 23.2\% (Jacobson \& Gould 2007; Swannell, Martin, Page, Hasking, \& St. John, 2014). Therefore, it is especially important to understand this phenomenon in adolescent populations.

\section{NSSI Definition}

Franklin \& Nock (2016) define NSSI using several distinct characteristics. First, while NSSI and suicidal behavior often co-occur (Andover \& Gibb, 2010), the act of nonsuicidal self-injury takes place without the intent to die. Some researchers have argued that NSSI and suicidal behavior are not distinguishable (Kapur, Cooper, O'Connor, \& Hawton, 2013); however, the bulk of research generally supports their separation (e.g., Muehlenkamp \& Gutierrez, 2004; Brausch \& Gutierrez, 2010). Second, NSSI is defined 
as an intentional act. In other words, accidental bodily harm is not included in the definition of NSSI. This aspect of NSSI suggests that the behavior must be goal-directed, as individuals deliberately engage in NSSI to achieve a specific outcome (Briere \& Gil, 1998). Third, NSSI involves direct harm to oneself. This component of the definition would exclude actions such as drinking excessively or smoking. These behaviors can cause bodily harm, but such harm usually occurs incidentally rather than being the primary intention of the individual (St. Germain \& Hooley, 2012). Fourth, NSSI does not include tissue-damaging behaviors that are considered more socially acceptable (e.g., piercings, tattoos). Research supports socially appropriate and inappropriate bodily injury as two distinct concepts (Favazza, 2012; Nock, 2009). Fifth, according to the Franklin and Nock (2016) definition, NSSI involves at least a moderate amount of injury. For example, minor self-injurious behaviors (e.g., skin-picking, lip-biting) are qualitatively different from moderate-to-severe NSSI behaviors (e.g., cutting, burning; LloydRichardson, Perrine, Dierker, \& Kelley, 2007; Klonsky \& Olino, 2008). Sixth, NSSI does not include minor, repetitive self-injury (e.g., head-banging) that is associated with developmental disorders or major self-injury (e.g., self-amputation) that is associated with psychotic or dissociative disorders. Both of those types of self-injury have been found to be qualitatively different from NSSI (Nock \& Favazza, 2009).

\section{The Clinical Presentation of NSSI}

Recent literature has suggested NSSI as a potential disorder in the Diagnostic and Statistical Manual of Mental Disorders (DSM-5; American Psychiatric Association, 2013); however, it has been determined that more research is needed to establish NSSI disorder criteria (Selby, Bender, Gordon, Nock, \& Joiner, 2011; Zetterqvist, 2015). 
Currently, NSSI is a feature that is associated with a range of psychopathology (Nitkowski \& Petermann, 2011). Research has long supported the relationship between NSSI and Borderline Personality Disorder (BPD); furthermore, NSSI is considered a core feature of BPD (e.g., Linehan, 1993). In addition to BPD, elevated rates of NSSI have been associated with symptoms of anxiety (Jacobson \& Gould, 2007; Brunner et al., 2007; Selby et al., 2011) and depression (Brunner et al., 2007; Hankin \& Abela, 2011; Cox et al., 2012; Marshall, Tilton-Weaver, \& Stattin, 2013). Finally, NSSI is typically associated with increased levels of suicidality (Nock et al., 2006; Lloyd-Richardson et al., 2007; Tang et al., 2011; Cox et al., 2012).

Theories of the Development of NSSI

One of the earlier theories of the etiology of non-suicidal self-injury is Linehan's biosocial theory of borderline personality disorder (BPD; Linehan, 1993). This theory posits that the combination of vulnerability to strong emotions and lack of emotion regulation skills in individuals with BPD results in maladaptive coping behaviors, such as NSSI. Linehan's model also suggests that invalidating environments further increase likelihood for self-injury, as individuals who are discouraged from expressing emotions are less likely to possess a range of adaptive emotion regulation skills. While this theory provides an explanation for the link between BPD and NSSI, self-injurious behavior also occurs outside of BPD. Thus, other theoretical models are important to consider when understanding NSSI engagement.

Another theory of the origins of self-injury is the Experiential Avoidance Model (EAM; Chapman, Gratz, \& Brown, 2006). The EAM proposes that individuals first engage in NSSI as a means of escaping high levels of emotional distress. When self- 
injury provides relief from unwanted emotions, this avoidance of distress is negatively reinforcing for the individual. In other words, an individual who is unable to manage emotional responses to stressors will engage in NSSI to avoid emotional pain. This avoidance provided by the NSSI will lessen emotional distress, thereby increasing the likelihood that the individual will self-injure in response to future stressors. Recent literature has offered support for the EAM in a sample of young adults (Anderson \& Crowther, 2012) and adolescents (Howe-Martin, Murrell, \& Guarnaccia, 2012).

Finally, Nock and Prinstein (2004) proposed a four-factor model for NSSI function that is based on learning/conditioning theories. This model includes two dichotomous dimensional categories: automatic vs. social and positive reinforcement vs. negative reinforcement. These dimensions can be combined to form four NSSI functions: automatic-positive reinforcement (e.g., generating feeling), automatic-negative reinforcement (e.g., relieving negative emotions), social-positive reinforcement (e.g., communicating distress to others, fitting in with peers), and social-negative reinforcement (e.g., avoiding unpleasant activities, avoiding punishment from others). Findings using this theoretical model have been mixed, with some studies reporting that automatic functions are most commonly endorsed (Nock \& Prinstein, 2004; Klonsky \& Glenn, 2009; Zetterqvist, Lundh, Dahlström, \& Svedin, 2013) and another study reporting equal endorsement of automatic and social functions (Lloyd-Richardson et al., 2007).

\section{Risk Factors for NSSI}

Previous research has related NSSI to a host of individual and environmental risk factors. As suggested by the Experiential Avoidance Model, it is common for individuals to utilize self-injury as a means of avoiding painful thoughts or emotions. Thus, NSSI 
may serve as a coping mechanism for individuals who have experienced childhood trauma. For example, childhood maltreatment (Gratz, 2006) is a well-established risk factor for NSSI engagement. More specifically, experiences involving childhood sexual abuse (Gratz, Conrad, \& Roemer, 2002; Gratz, 2003; Jacobson \& Gould, 2007); childhood physical abuse (Gratz, 2003); childhood separation from parents (Gratz, Conrad, \& Roemer, 2002; Gratz, 2003); and more general childhood trauma (Heath, Toste, Nedecheva, \& Charlebois, 2008) are all associated with higher levels of NSSI engagement later in life.

As Linehan's biosocial theory of BPD suggests, more general interpersonal factors are also relevant during an individual's development. Nock and Prinstein's model of NSSI function (2004) also proposes that NSSI can be socially reinforcing for individuals; thus, interpersonal factors are important to consider alongside self-injury. In terms of social factors, prior literature has shown that family and peer interactions are strongly associated with NSSI engagement. NSSI engagement is broadly associated with poor relationship quality (MacLaren \& Best, 2010; Hankin \& Abela, 2011), as well as higher levels of conflict with family and peers (Adrian, Zeman, Erdley, Lisa, \& Sim, 2011). In terms of family interactions, research suggests that poor familial support is a strong predictor of NSSI (Andrews et al., 2014; Tatnell, Kelada, Hasking, \& Martin, 2014). In addition, poor attachment to caregivers is associated with NSSI onset and maintenance (Gratz, Conrad, \& Roemer, 2002; Gratz, 2003; Tatnell et al., 2014). Finally, one's perceptions of peer engagement in depressive or self-injurious behaviors may be a contributing factor to NSSI (Prinstein et al., 2010). 
While some NSSI risk factors are more environmental in nature, others are more cognitive or affective. In fact, a robust literature exists regarding cognitive and affective factors that are associated with NSSI. In general, having a negative cognitive style (Hankin \& Abela, 2011) and experiencing negative affect more intensely (Gratz, 2006; Victor \& Klonsky, 2013) are related to risk for NSSI. Other important cognitive-affective risk factors include the tendency to ruminate (Najmi, Wegner, \& Nock, 2007; Nock \& Mendes, 2008; Selby, Franklin, Carson-Wong, \& Rizvi, 2013), poor problem-solving or coping abilities (Nock \& Mendes, 2008; Andrews et al., 2014), and low levels of distress tolerance (Nock \& Mendes, 2008). These factors are important, as they may increase the likelihood NSSI will become reinforcing as a means of avoiding unwanted thoughts or emotions.

NSSI and Emotion Dysregulation

Many theories surrounding self-injury have indicated that the inability to cope with unwanted emotions is a core component of NSSI onset and maintenance. Therefore, it makes sense that one of the most established affective factors related to NSSI is emotion dysregulation. Emotion dysregulation is a term used to describe the inability to experience, understand, or control one's emotions (Gratz \& Roemer, 2004). It is thought that emotion dysregulation is linked to NSSI engagement because NSSI represents an attempt to alleviate unwanted thoughts or emotions (Briere \& Gil, 1998; Bresin \& Gordon, 2013; Franklin et al., 2010). More specifically, individuals who are unable to manage their emotions effectively are more prone to use NSSI as a means of maladaptive emotion regulation (Linehan, 2003). 
In a review by Klonsky (2007), desiring to regulate emotions was the most commonly endorsed motivation for NSSI among all studies using adolescent samples. There is a large body of literature supporting the relationship between emotion dysregulation and NSSI among adolescents, though this effect has been studied using primarily inpatient adolescent samples (Nixon, Cloutier, \& Aggarwal, 2002; Kumar et al., 2004; Nock \& Prinstein, 2004; Adrian et al., 2011). There is evidence that these findings can be generalized to other populations; for example, support for the relationship between emotion dysregulation and NSSI has also been found in nonclinical (Laye-Gindhu \& Schonert-Reichl, 2005) and forensic (Penn, Esposito, Schaeffer, Fritz, \& Spirito, 2003) samples.

Emotion dysregulation is often studied as a unidimensional construct; however, there are multiple, distinct deficits associated with the inability to regulate emotions. To address the specific emotion dysregulation domains, Gratz \& Roemer (2004) created the Difficulties in Emotion Regulation Scale (DERS). This scale includes the following components of emotion dysregulation: nonacceptance of emotional responses, difficulties engaging in goal directed behavior, impulse control difficulties, lack of emotional awareness, limited access to emotion regulation strategies, and lack of emotional clarity. In a female undergraduate sample, limited access to emotion regulation strategies (i.e., the strategies subscale of the DERS) accounted for greater variance in NSSI beyond other aspects of ER measured by the DERS (Gratz \& Roemer, 2008). This finding is consistent with a more recent study using a sample of adolescent inpatients (Perez, Venta, Garnaat, \& Sharp, 2012), which showed that only limited access to emotion regulation strategies was significantly associated with NSSI engagement. In addition, a study by Turner, 
Chapman, \& Layden (2012) found that using NSSI as a means of emotion regulation was most strongly predicted by lack of access to emotion regulation strategies (i.e., the "strategies" subscale of the DERS). While the strategies subscale has repeatedly emerged as a contributor to NSSI, the impulse control difficulties and difficulties engaging in goaldirected behavior subscales have also demonstrated associations with self-injurious behavior (Heath et al., 2008; Franklin, Aaron, Arthur, Shorkey, \& Prinstein, 2012). NSSI and Emotion Reactivity

A recent study suggested that research on NSSI and emotion dysregulation may be improved by including emotion reactivity as a contributing factor (Franklin et al., 2012). Emotion reactivity differs from emotion dysregulation in that it represents more trait-like vulnerability to heightened emotional experiences, whereas emotion dysregulation represents the inability to manage those experiences (Mennin, Holaway, Fresco, Moore, \& Heimberg, 2007). While emotion dysregulation is key in understanding why individuals engage in NSSI, this construct does not fully capture the emotional experience leading up to self-injury. For example, an individual who does not experience strong unwanted emotions as often may be less likely to demonstrate emotion dysregulation than an individual who has frequent, intense emotional experiences. One might expect heightened emotionality and the inability to regulate emotions to work together in the development of maladaptive coping strategies. Therefore, it is understandable that another risk factor for NSSI is emotion reactivity (which has also been referred to as "emotional vulnerability" [Linehan, 1993]). Emotion reactivity refers to "the tendency to experience frequent and intense emotional arousal" (Karrass, Walden, Conture, Graham, Arnold, Hartfield, \& Schwenk, 2006). Those who are high in emotion 
reactivity tend to experience emotions more intensely, for a longer duration of time, and in response to a wider array of stimuli (Nock et al. 2008; Bresin, Gordon, Bender, Gordon, \& Joiner, 2010). Recent literature supports this relationship between emotion reactivity and emotion dysregulation by positing that emotion reactivity may increase one's likelihood of experiencing difficulties in emotion regulation (Nock, Wedig, Holmberg, Hooley, 2008). Salsman and Linehan (2012) conducted a study in which they examined relationships between negative emotion reactivity, emotion dysregulation, and BPD traits among college undergraduates. Results from this study indicated that negative emotion reactivity was most strongly associated with the lack of access to emotion regulation strategies and the goal-directed behavior subscales of the DERS. However, no studies to date have examined the relationship between overall emotion reactivity, DERS subscales, and NSSI among adolescents.

While a large amount of research has focused on emotion dysregulation and NSSI, much less work exists on the role of emotion reactivity in NSSI engagement. Gratz (2003) conducted a review on risk factors for NSSI and found that emotion reactivity was a significant predictor. Both low positive emotion reactivity and high negative emotion reactivity are strongly related to NSSI engagement among young adults (Gratz, 2006; Glenn, Blumenthal, Klonsky, \& Hajcak, 2011). To date, one of the only known studies that examines emotion reactivity and NSSI among adolescents was conducted by Nock and colleagues (2008), who used a combined sample of adolescents and young adults. In that study, findings indicated that emotion reactivity was significantly related to the presence of NSSI. Additionally, emotion reactivity served as a mediator between psychopathology and self-injurious thoughts and behaviors. 


\section{NSSI and Rumination}

When discussing emotion reactivity and emotion dysregulation, the cognitive process of rumination is an important contributing factor to consider. Rumination (NolenHoeksema, 1991) has been largely defined in the literature as the process of repeatedly thinking about one's experiences and their reactions to those events (Nolen-Hoeksema, Wisco, \& Lyubomirsky, 2008). Much of the existing research on rumination has focused on dysphoric rumination, or recalling one's unpleasant emotions and experiences (NolenHoeksema et al., 2008). Selby, Anestis, and Joiner (2008) proposed that rumination is a primary driving force behind "cascades of emotions," or circumstances in which individuals enter a cycle of aversive emotional responses to negative experiences. In fact, rumination has been shown to amplify the intensity and duration of negative emotions such as depression (Donaldson \& Lam, 2004; Lavender \& Watkins, 2004) or anger (Ray, Wilhelm, \& Gross, 2008; Rusting \& Nolen-Hoeksema, 1998). Given the association between NSSI and emotion dysregulation (Bresin \& Gordon, 2013; Franklin et al., 2010), it is unsurprising that rumination and NSSI have also been linked in a number of studies using adult samples (Arbuthnott, Lewis, \& Bailey, 2015; Hoff \& Muehlenkamp, 2009; Nikolai, Wielgus, \& Mezulis, 2016; Richmond, Hasking, \& Meaney, 2017; Selby et al., 2013). While there is some evidence that rumination is associated with NSSI among community samples of adolescents (Barrocas, Giletta, Hankin, Prinstein, \& Abela, 2015; Hilt, Cha, \& Nolen-Hoeksema, 2008; Voon, Hasking, \& Martin, 2014a), the literature is far less robust among this age group. 


\section{Current Study}

Prior literature has shown support for a relationship between emotion reactivity and NSSI engagement, yet few studies have included adolescents and no studies have focused solely on this age group. Thus, the first aim of the current study is to extend previous work by examining emotion reactivity as a contributing factor to frequency of NSSI engagement. It is expected that emotion reactivity will be significantly related to NSSI frequency (Hypothesis 1). Next, it is suggested that emotion reactivity is related to emotion dysregulation. However, it is possible that certain facets of emotion dysregulation are more significantly associated with emotion reactivity than others. The second aim of the current study is to further understand how emotion reactivity is related to specific difficulties in emotion regulation. Based on a similar previous study (Salsman \& Linehan, 2012), it is expected that emotion reactivity will be most significantly associated with the "Strategies" and "Goals" subscales of the DERS (Hypotheses $2 a$ and $2 b)$. The third aim of this study is to extend prior studies on difficulties in emotion dysregulation and NSSI by measuring this phenomenon among a group of at-risk adolescents within a residential facility. Consistent wit previous findings, it is hypothesized that limited access to emotion regulation strategies will be most salient in terms of NSSI frequency (Hypothesis 3). The fourth aim of the current study is to further examine the link between rumination and NSSI frequency in an at-risk adolescent sample. It is expected that rumination will be significantly and positively related to NSSI frequency (Hypothesis 4). Fifth, this study aimed to replicate previous findings that associate rumination with emotion reactivity and emotion dysregulation in a sample of atrisk youth. Rumination is expected to be significantly and positively relate to both 
emotion reactivity and emotion dysregulation in this sample (Hypotheses $5 a$ and $5 b$ ). Finally, given that emotion reactivity describes a heightened emotionality and emotion dysregulation involves the inability to manage one's emotions, it is possible that emotion dysregulation may serve as a mediator between emotion reactivity and NSSI frequency. The final aim of the current study is to test a multiple mediation model which compares the relative strength of different facets of emotion dysregulation as mediators between emotion reactivity and NSSI. As the final test is exploratory in nature, no specific predictions can be made regarding which specific emotion regulation difficulties will be the most significant mediators. 


\section{CHAPTER II - METHOD \\ Participants}

Previous literature suggests medium-large effect sizes for hypotheses 1 and 3 (Nock et al., 2008 and Gratz \& Tull, 2010, respectively), as well as a medium effect size for hypotheses 2a and 2b (Salsman \& Linehan, 2012). It has been suggested that a sample size of $N>50+8 \mathrm{~m}$ (where $\mathrm{m}$ is the number of independent variables) is required to detect medium effect sizes at $80 \%$ power with an alpha at .05 (Green, 1991; Tabachnick \& Fidell, 2007). As the current study included nine independent variables, a sample size of at least 122 participants was needed to have adequate statistical power to detect the expected effect.

The initial pool of participants for the current study included 564 adolescents ranging in age from 16 to 19 years $(M=16.76, S D=.71)$. Among those who participated, $106(18.8 \%)$ reported a history of NSSI engagement and were included in the further analyses. Participants were recruited from a residential facility in the Southeastern United States and are considered "at-risk" for negative life outcomes, as many have dropped out of school or have made contact with the legal system. Youths voluntarily enroll in the facility's program, though many are encouraged to attend by family members or other adults in their lives. The 22-week program functions primarily as an educational institution, but also offers opportunities such as vocational training, military preparation skills, and community service.

\section{Measures}

\section{Demographic Factors}


All participants provided information for a host of demographic variables, including age, sex, race, who they were primarily raised by, arrest history, and school dropout status.

\section{Emotional Reactivity}

The Emotion Reactivity Scale (ERS; Nock et al., 2008) is a self-report questionnaire designed to assess emotion reactivity and its subcomponents. The 21-item scale includes items measuring emotion sensitivity (e.g., "I tend to get emotional very easily"), emotion intensity (i.e., "When I experience emotions, I feel them very strongly/intensely"), and emotion persistence (i.e., "When I am angry/upset, it takes me much longer than most people to calm down"). Items are rated on a 5-point scale, with response values ranging from 0 ("not at all like me") to 4 ("completely like me"). Scores on individual items are summed to create an overall ERS score and three subscale scores. The current study focuses on the overall emotion reactivity score, with higher values indicating greater levels of emotional reactivity. The ERS has demonstrated high internal consistency $(\alpha=.94)$, as well as criterion-related validity when measured alongside NSSI.

\section{Emotion Dysregulation}

The Difficulties in Emotion Regulation Scale (DERS; Gratz \& Roemer, 2004) is a self-report questionnaire is used to assess distinct areas in which individuals may struggle to regulate their emotions. This 36-item measure includes both normal and reverse-coded items that examine emotion dysregulation in the following domains: nonacceptance of negative emotional responses (Nonacceptance; e.g., "When I'm upset, I feel guilty for feeling that way"), difficulties engaging in goal-directed behavior when distressed 
(Goals; e.g., "When I'm upset, I can still get things done”), difficulties controlling impulses when distressed (Impulse; e.g., "When I'm upset, I feel out of control”), lack of emotional awareness (Awareness; e.g., "When I'm upset, I acknowledge my emotions”), limited access to emotion regulation strategies (Strategies; e.g., "When I'm upset, I believe that I will remain that way for a long time"), and lack of emotional clarity (Clarity; e.g., "I am confused about how I feel"). All DERS items are rated on a 5-point scale, with response values ranging from 1 to $5(1=$ "almost never," $2=$ "sometimes," $3=$ "about half the time," 4 = "most of the time," and 5 = "almost always"). Scores on individual items are summed to create an overall DERS score and six subscale scores. The current study focuses on the six subscale scores, with higher values indicating greater emotion dysregulation in that specific domain. The DERS has demonstrated strong internal consistency $(\alpha=.93)$ and strong predictive validity in terms of NSSI frequency (Gratz \& Roemer, 2004).

\section{Anger Rumination}

Rumination was also assessed using the Anger Rumination Scale (ARS; Sukhodolsky, Golub, \& Cromwell, 2001), a self-report instrument that measures one's tendency to repeatedly recall previous moods and experiences that are specific to anger. The ARS is comprised of 19 items that load onto four discrete factors: angry afterthoughts ("Whenever I experience anger, I keep thinking about it for a while"), thoughts of revenge ("I have difficulty forgiving people who have hurt me"), angry memories ("I keep thinking about events that angered me for a long time"), and understanding of causes ("I think about the reasons people treat me badly"). All items are rated on a 4-point Likert scale, with response options ranging from $1=$ "almost never" to 
4 = "almost always." Items are summed to create an ARS total score and four subscale scores, with higher scores indicating a greater tendency to ruminate about anger and anger-provoking experiences. ARS total and its subscales have demonstrated adequate reliability and validity (all $\alpha s>.72$; Sukhodolsky et al., 2001).

NSSI Frequency

The Self-Injurious Thoughts and Behaviors Interview Short-Form Self-Report (SITBI-SF-SR) examines a number of characteristics (e.g., presence, frequency, severity) related to suicide and NSSI. This measure was originally designed as a structured interview (Nock, Holmberg, Photos, \& Michel, 2007), which demonstrated strong interrater reliability (average $\kappa=.99$ ) and strong concurrent validity with other NSSI measures (average $\kappa=.87$ ). The interview has since been modified for use as a self-report questionnaire (Muehlenkamp, Walsh, \& McDade, 2010). The NSSI thoughts and NSSI behaviors portions of the SITBI-SF-SR will be the focus of this study. These sections ask participants about NSSI characteristics such as age of onset, NSSI frequency, NSSI method, and NSSI severity. The proposed model in the current study focuses specifically on frequency of NSSI behavior across one's lifetime. The item that assesses this is typically an open-ended question; however, previous literature has modified the questionnaire to include fixed responses. In a previous study examining lifetime NSSI frequency, Heath and colleagues (2008) created the following response choices: "1," "2-4," "5-10," "11-50," "51-100," and "more than 100 times.” The current study will follow the same procedure, with lifetime NSSI frequency assessed using the same response options. 


\section{Procedure}

The affiliated university's Institutional Review Board has approved all procedures for the current study. The director of the residential program, who serves as the guardian ad litem for youths during their enrollment, agreed to allow this study to be conducted at the facility. In addition, the program director provided written consent for youths to be invited to participate. Prior to participation, all participants provided written informed consent (if 18 years or older) or assent (if younger than 18 years). Participation in this study was voluntary and youth were not compensated; however, participation rates were expected to be high as prior studies at the program have typically had $90 \%$ or higher participation. The program enrolls new youth at two time points during the year and up to 200 youths are admitted in each cycle. All youths in the program were asked to participate in the current study. Prior data on NSSI collected in an earlier wave found that nearly $50 \%$ of youths in the program reported a history of NSSI. Therefore, it was expected that an $n$ of 130 youth who engaged in NSSI could be achieved in 2-3 program cycles. Self-report measures were administered to groups of youth in classrooms on the residential facility's campus via computer survey software (Qualtrics, Provo, UT). Data collection was overseen by a team of trained research assistants.

\section{Data Analysis}

All data analyses were conducted using SPSS statistical software (IBM Corporation, 2015). Before running any analyses, the data were screened for excessive missing data and outliers. If necessary, missing data was handled using an appropriate imputation technique. If any extreme outliers were present, those cases were dealt with 
appropriately to preserve the meaningfulness and accuracy of the data. In addition, due to experimenter error, only a subset of participants completed ARS measures $(N=87)$.

\section{Preliminary Analyses}

Descriptive statistics (i.e., means, standard deviations, and bivariate correlations) for ERS total score, CERQ-Rumination score, ARS total score, DERS Total score, DERS subscale scores, and NSSI frequency were calculated. Preliminary analyses also examined group differences in all independent variables and NSSI across age, sex, and race. Demographic variables that yielded significant differences on variables of interest were considered as covariates in further analyses.

\section{Correlations}

Hypotheses 1 through 5 were tested using appropriate statistical techniques given the nature of the data (e.g., normality of the dependent variable, categorial versus ordinal nature of the independent variable). First, to test Hypothesis 1, the bivariate correlation between overall ERS score and NSSI frequency was calculated. To test Hypotheses 2a and $2 b$, bivariate correlations between overall ERS score and the six DERS subscales were calculated. Hypothesis 3 was tested similarly, using bivariate correlations between the six DERS subscales and NSSI frequency. Hypothesis 4 was tested by correlating ARS Total with NSSI frequency. Hypotheses $5 \mathrm{a}$ and $5 \mathrm{~b}$ were tested by correlating ARS Total scores with ERS Total and DERS Total.

\section{Multiple Mediation Model}

To examine the variance within the NSSI and emotion reactivity association that is accounted for by aspects of emotion dysregulation, a multiple mediation model was tested. In this model, the independent variable was the overall ERS score, the dependent 
variable was NSSI frequency, and the six DERS subscales served as mediators. A nonparametric bootstrapping method (Preacher and Hayes, 2008) was used to test the multiple mediation model, as this program is designed with the ability to include multiple mediators simultaneously rather than an individual test for each mediator. In addition, bootstrapping has been shown to be the most powerful, the most appropriate for a small sample size, and the least susceptible to Type I error. Unlike more traditional methods of analysis, Preacher and Hayes's method does not require normality assumptions to test indirect effects. Instead, indirect effects are estimated using bias-corrected confidence intervals (CIs). In the current study, the bootstrap method included resampling 5,000 times to generate $95 \%$ CIs for indirect effects without a loss of statistical power (as recommended per Davidson \& MacKinnon, 2000). An indirect effect (i.e., mediation effect) was considered significant if the CI did not include zero. Beta regression weights indicated the magnitude of the indirect effect sizes for each specific path in the model.

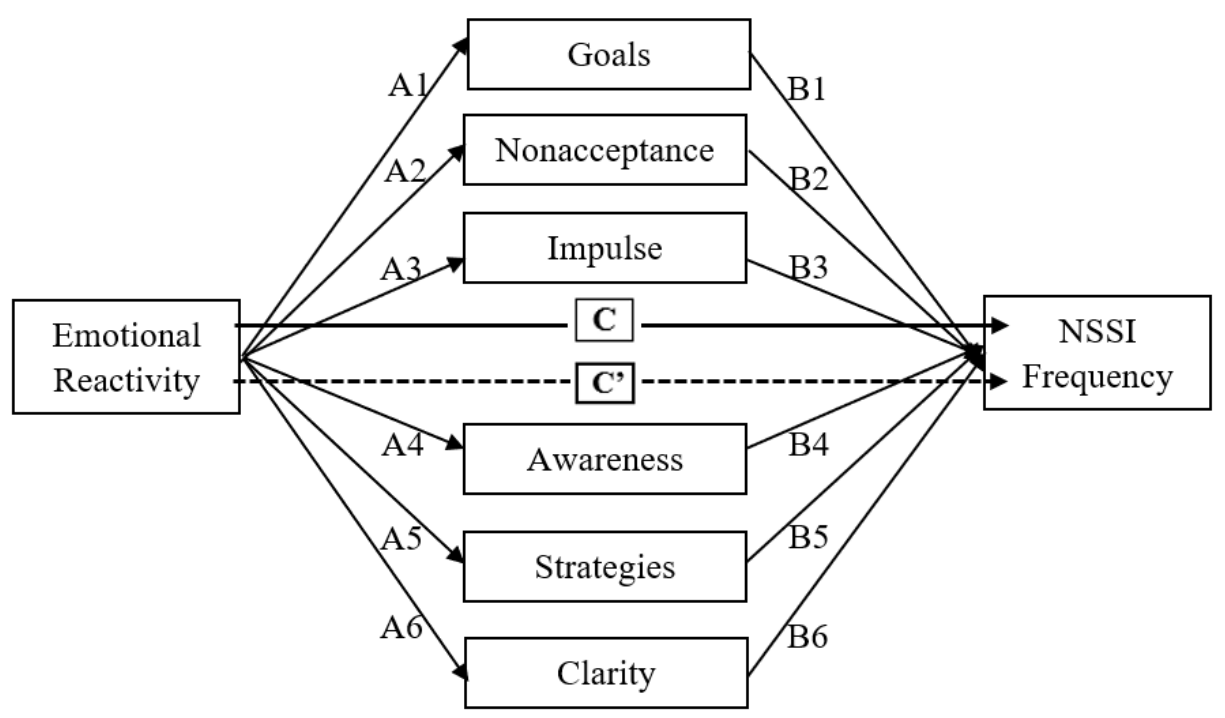

Figure 1. Proposed multiple mediation model 
Figure 1 offers a depiction of the proposed multiple mediation model. In this model, "A" paths represent the association between the total ERS score and the six DERS subscales. The "B" paths represent the association between the six DERS subscales and NSSI frequency while controlling for the total ERS score. The "C" path in the model represents what is known as the "total effect," or the association between total ERS score and NSSI frequency. Finally, the "C"" path represents the effect of total ERS score on NSSI frequency after controlling for the six DERS subscales. 


\section{CHAPTER III - RESULTS \\ Missing Data}

Approximately one-fourth of participants $(N=25)$ were missing data for at least one variable, with $5.4 \%$ of data missing altogether. Therefore, patterns of missing data were examined. Data did not appear to be missing systematically (e.g., a single item on a scale being unanswered, with content highly variable across participants). Little's test of missing completely at random (MCAR; Little, 1988) was performed and data were determined to be missing completely at random $\left(\chi^{2}(28)=21.91, p=.79\right)$. Given that data was MCAR and only a small percentage of data were missing, hot deck imputation (Myers, 2011) was used to replace missing values. This method involves imputing a single value for a missing data point by estimating the value based on donor cases with similar demographic characteristics (in this study, age, sex, and race were used to identify similar cases). Hot deck imputation replaced missing data for all DERS total, DERS subscale, and ERS total scores. There were no missing values on the age, sex, or race variables and missing data related to NSSI was not imputed. After imputation was complete, a final sample of 106 participants was retained for further analyses.

\section{Demographic Comparisons}

The mean age among the NSSI-only sample was $16.72(S D=.74)$. The sample was predominantly male $(N=65 ; 61.3 \%)$. In addition, a large majority of participants were White/Caucasian (76.4\%), followed by Black/African American (12.3\%), Hispanic/Latinx (3.8\%), Multiracial (3.8\%), Other (2.8\%), and Asian/Pacific Islander $(0.9 \%)$. Given the lack of variability in race, this variable was collapsed into "White" $(N$ $=77 ; 75.5 \%)$ and "non-White" $(N=25 ; 24.5 \%)$ categories for subsequent analyses. 
Around one-fourth (26.4\%) of participants were raised by both biological parents, with over half $(57.5 \%)$ reporting that they were raised by one biological parent (primarily their biological mother) and $16 \%$ reporting that they were raised by someone other than their biological parents. Among this sample, $30.2 \%$ of participants endorsed an arrest history and $84 \%$ indicated that they had dropped out of school (with poor academic performance being cited as the most common reason for dropping out). Finally, the most commonly endorsed frequency of NSSI was 2-4 times $(N=24 ; 23.5 \%)$, followed closely by 11-50 times $(N=23 ; 22.5 \%)$. Relatively fewer youths reported engaging in NSSI 5-10 times $(N$ $=18 ; 17.6 \%), 100$ or more times $(N=17 ; 16.7 \%)$, only 1 time $(N=11 ; 10.8 \%)$, or $51-$ 100 times $(N=9 ; 8.8 \%)$. Because only nine participants endorsed engaging in NSSI " 51 100 times," the NSSI frequency responses were recoded as "1 time," "2-4 times," "5-10 times," "11-50 times," and "more than 50 times," with those responding with either "51100 " or "more than 100 times" being placed in the latter group. This updated NSSI frequency variable was used in all further analyses.

\section{Age Comparisons}

All comparisons based on demographic groups are presented in Table 1. Given that all variables were normally distributed or only slightly skewed, independent-samples t-tests and bivariate correlations were used to test differences on the primary variables of interest based on age, sex, and race. Bivariate correlations revealed a significant negative relationship between age and NSSI frequency $(r=-.198, p<.05)$. No other associations between age and any of the independent variables were statistically significant (all $p \mathrm{~s}>$ $.10)$. 


\section{Sex Comparisons}

Sex differences in NSSI frequency were nonsignificant $(t(104)=-.103, p=.918)$. Males reported greater difficulties controlling impulses when dysregulated (DERS Impulse) as compared to females $(t(104)=2.19, p<.05)$. On the other hand, females had higher scores on nonacceptance of emotional responses (DERS Nonacceptance) than their male counterparts $(t(104)=-2.01, p<.05)$. Sex differences for all other independent variables were nonsignificant (all $p \mathrm{~s}>.10)$.

\section{Race Comparisons}

No differences in NSSI frequency were observed across race (White vs. nonWhite) $(t(104)=1.11, p=.270)$. However, a couple of racial differences emerged when examining independent variables. Non-White participants reported significantly higher difficulties accessing emotion regulation strategies (DERS Strategies) compared to their White counterparts $(t(104)=-2.36, p<.05)$. Racial differences for all other independent variables were nonsignificant (all $p \mathrm{~s}>.10)$. 
Table 1 Demographic comparisons

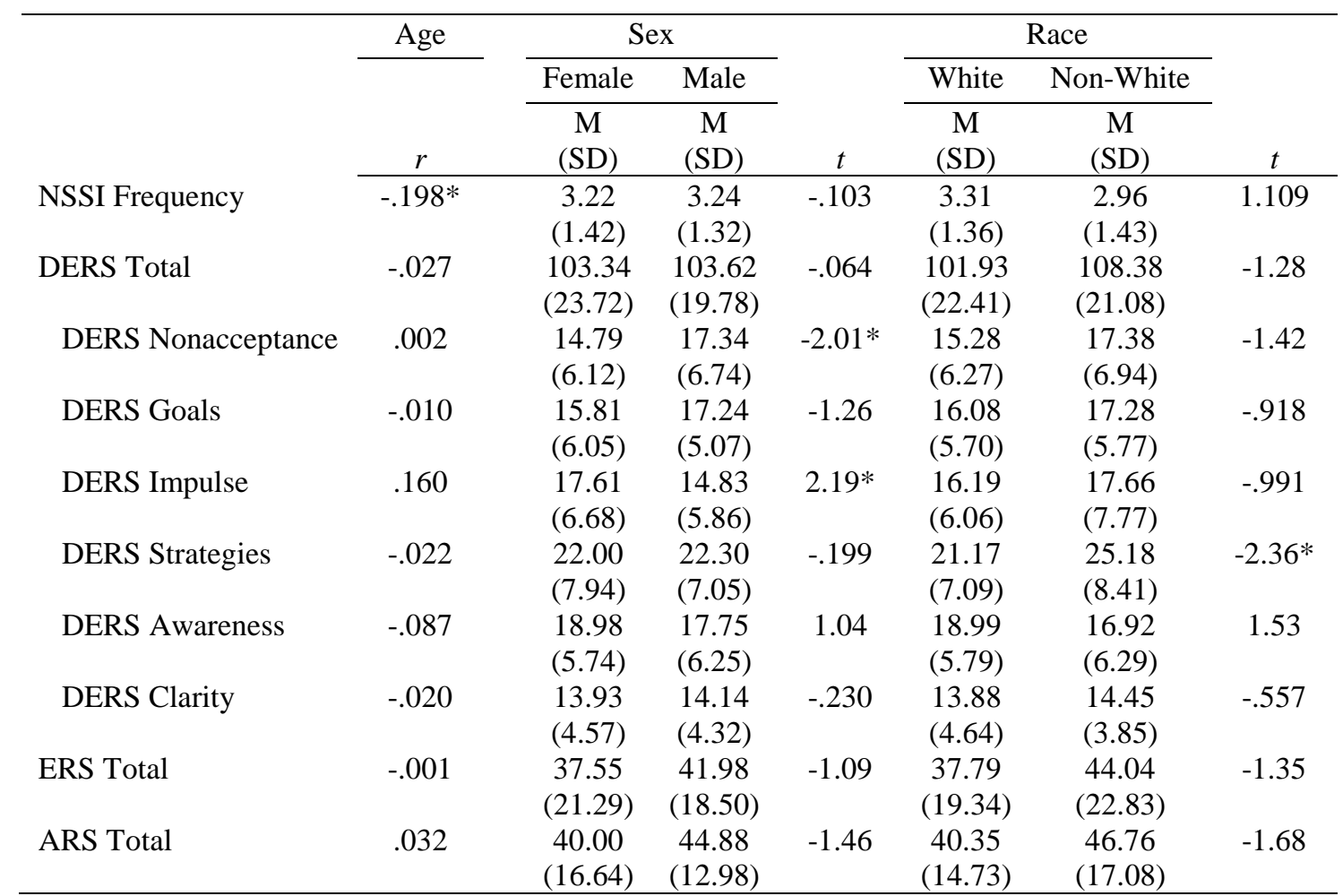

Note. ${ }^{* * p} p .01 * p<.05$

\section{Correlations}

To test associations between independent variables and NSSI frequency, bivariate correlations were performed using NSSI frequency (see Table 2 for these results). NSSI frequency was significantly and positively related to DERS Awareness $(r=.239, p<$ .05). All other relationships between NSSI frequency and independent variables were nonsignificant (all $p \mathrm{~s}>.10)$. 
Table 2 Correlations between IVs and NSSI frequency

\begin{tabular}{lcc}
\hline Variable & $r$ & $p$ \\
\hline DERS Total & .125 & .203 \\
DERS Nonacceptance & -.009 & .924 \\
DERS Goals & -.008 & .939 \\
DERS Impulse & -.094 & .338 \\
DERS Strategies & .079 & .419 \\
DERS Awareness & .239 & $.013^{*}$ \\
DERS Clarity & .140 & .151 \\
ERS Total & -.040 & .681 \\
ARS Total & -.162 & .130 \\
\hline Note. **p $<.01 * \mathrm{p}<.05$ & &
\end{tabular}

Bivariate correlations were also used to test relationships among all independent variables (see Table 3 for all correlations). Notably, ERS Total was significantly related to DERS Total $(r=.372, p<.001)$, DERS Goals $(r=.356, p<.001)$, DERS Impulse $(r=$ $.483, p<.001)$, and DERS Strategies $(r=.508, p<.001)$. ARS Total was significantly related to ERS Total $(r=.401, p<.001)$, DERS Impulse $(r=.282, p<.01)$, DERS Strategies $(r=.242, p<.05)$, and DERS Clarity $(r=.317, p<.01)$.

Table 3 Correlations between independent variables

\begin{tabular}{lcccccccc}
\hline Variable & 1 & 2 & 3 & 4 & 5 & 6 & 7 & 8 \\
\hline 1. DERS Total & & & & & & & & \\
2. DERS Nonacceptance & $.579^{* *}$ & & & & & & & \\
3. DERS Goals & $.649^{* *}$ & $.305^{* *}$ & & & & & & \\
4. DERS Impulse & $.571^{* *}$ & .119 & $.340^{* *}$ & & & & & \\
5. DERS Strategies & $.787^{* *}$ & $.509^{* *}$ & $.510^{* *}$ & $.463^{* *}$ & & & & \\
6. DERS Awareness & .175 & $-.197^{*}$ & -.068 & -.026 & -.107 & & & \\
7. DERS Clarity & $.610^{* *}$ & $.400^{* *}$ & $.310^{* *}$ & $.256^{* *}$ & $.253^{* *}$ & $.235^{* *}$ & & \\
8. ERS Total & $.389^{* *}$ & .132 & $.368^{* *}$ & $.479^{* *}$ & $.515^{* *}$ & -.078 & .108 & \\
9. ARS Total & .186 & .132 & .115 & $.279^{* *}$ & $.237^{*}$ & -.180 & $.316^{* *}$ & $.395^{* * *}$ \\
\hline Note. **p $<.01 * \mathrm{p}<.05$ & & & & & & & &
\end{tabular}




\section{Multiple Mediation Model}

The proposed multiple mediation model was tested using the SPSS PROCESS macro (Hayes, 2017) and included: (1) ERS Total as the "X" variable; (2) NSSI frequency as the "Y" variable; (3) DERS subscales as "M" variables; and (4) age, gender, and ethnicity as covariates. See Figure 2 for the results of the mediation analyses. In step 1 of the model, the regression of ERS Total on NSSI frequency without considering mediators was nonsignificant, $(b=-.002, p=.761)$. Step 2 showed that ERS Total was a significant predictor for some mediators, including DERS Goals $(b=.100, p<.001)$, DERS Impulse $(b=.161, p<.001)$, and DERS Strategies $(b=.186, p<.001)$ subscales. In Step 3 of the mediation process, no DERS subscales significantly predicted NSSI frequency. Finally, step 4 of the analysis revealed that ERS Total did not significantly predict NSSI frequency while controlling for DERS subscales $(b=-.005, p=.558)$. Effect sizes for all associations in the model were negligible (all $d \mathrm{~s}<.20$ ).

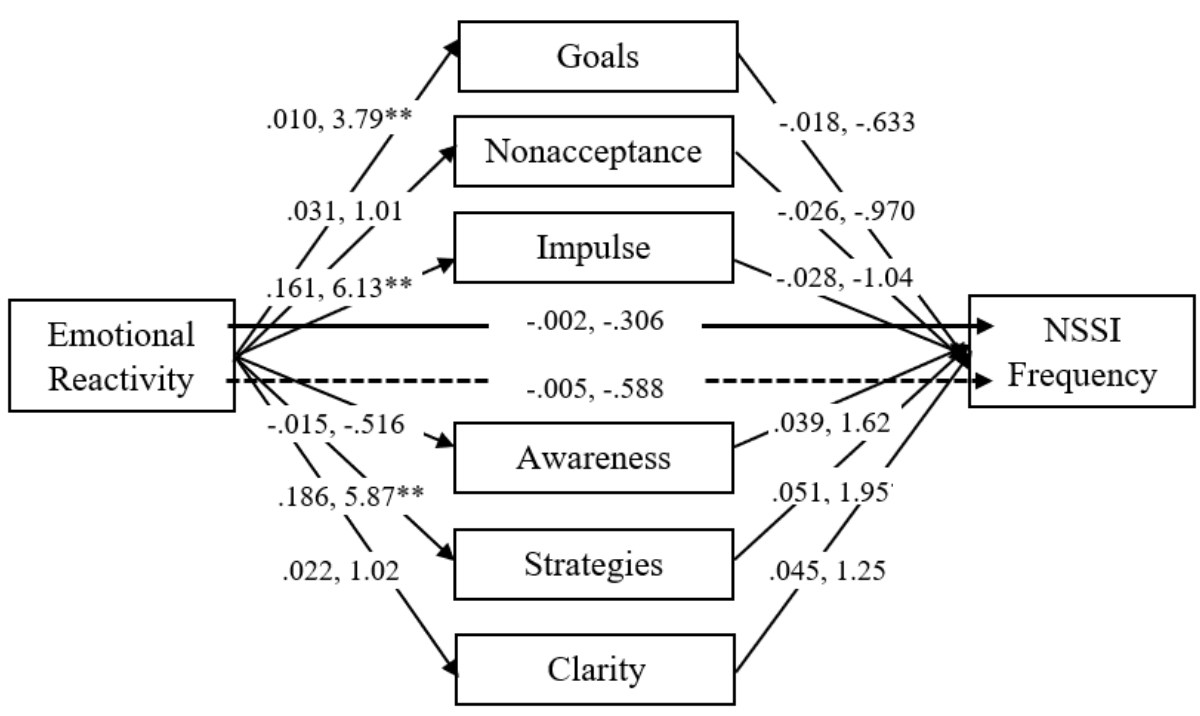

Figure 2. Multiple mediation model results Note. $* * \mathrm{p}<.01,{ }^{*} \mathrm{p}<.05$ 


\section{Alternative Mediation Models}

Because the proposed model did not yield the hypothesized results, alternative mediation models were examined. First, DERS Total (rather than DERS subscale scores) was tested as a mediator between ERS Total and NSSI frequency. ERS Total was a significant predictor of DERS Total $(b=.419, p<.001)$, but not NSSI frequency $(b=-$ $.002, p=.761)$. The regression of DERS Total on NSSI was also nonsignificant $(b=$ $.011, p=.102)$. ERS Total did not significantly predict NSSI frequency while controlling for DERS Total $(b=-.007, p=.362)$ and the effect size for this association was negligible $(d<.20)$. A series of mediation analyses were also conducted to test each DERS subscale separately as a mediator between ERS Total and NSSI frequency; however, the results of those analyses were similar to those reported above.

\section{Alternative Moderation Model}

Next, DERS Total was tested as a moderator between ERS Total and NSSI frequency to examine whether there is an interactive effect between emotion reactivity and emotion dysregulation in predicting NSSI frequency. The moderation model was tested using the SPSS PROCESS macro (Hayes, 2017). The overall model was nonsignificant $\left(R^{2}(6,99)=.103, p=.090\right)$. ERS Total $(b=-.006, p=.380)$, DERS Total $(b=.009, p=.166)$, and the interaction term $(b=-.0004, p=.129)$ were all nonsignificant predictors of NSSI frequency.

\section{Alternative Regression Models}

Finally, given that ERS Total was not significantly associated with NSSI frequency in prior analyses, an ordinal logistic regression was performed including DERS subscales, age, gender, and ethnicity as predictors of NSSI frequency. The overall model 
was significant $\left(\chi^{2}(9)=28.78, \mathrm{p}<.01\right)$. While controlling for other variables in the model, main effects were found for age $\left(\chi^{2}(1)=7.64, \mathrm{p}<.01\right)$, non-White ethnicity $\left(\chi^{2}(1)\right.$ $=3.81, \mathrm{p}<.05)$, DERS Strategies $\left(\chi^{2}(1)=5.47, \mathrm{p}<.05\right)$, and DERS Awareness $\left(\chi^{2}(1)=\right.$ $7.51, \mathrm{p}<.01)$. Results from the regression model can be found in Table 4 .

Table 4 DERS subscales as predictors of NSSI frequency

\begin{tabular}{lcccc}
\hline Variable & $\mathrm{B}$ & $\chi^{2}$ & $d f$ & $p$ \\
\hline Female & .608 & 2.19 & 1 & .139 \\
Non-White & -.906 & 3.81 & 1 & .051 \\
Age & -.740 & 7.64 & 1 & $.006^{* *}$ \\
DERS Nonacceptance & -.044 & 1.36 & 1 & .243 \\
DERS Goals & -.011 & .095 & 1 & .758 \\
DERS Impulse & -.036 & 1.00 & 1 & .316 \\
DERS Strategies & .083 & 5.47 & 1 & $.019^{*}$ \\
DERS Awareness & .094 & 7.51 & 1 & $.006^{* *}$ \\
DERS Clarity & .067 & 1.87 & 1 & .172 \\
\hline Note $* *$ p $<01, * 0505$ & & & &
\end{tabular}

Another ordinal logistic regression was performed including DERS Total, ARS

Total, age, gender, and ethnicity as predictors of NSSI frequency. The overall model was significant $\left(\chi^{2}(5)=19.42, p<.01\right)$. In this model, main effects were found for age $\left(\chi^{2}(1)\right.$ $=8.73, p<.01)$, non-White ethnicity $\left(\chi^{2}(1)=6.17, p<.05\right)$, and DERS Total $\left(\chi^{2}(1)=\right.$ $5.03, p<.05)$. There was no main effect, however, for ARS Total $(p>.10)$. See Table 5 for results from this regression model.

Table 5 DERS and ARS as predictors of NSSI frequency

\begin{tabular}{lcccc}
\hline Variable & $\mathrm{B}$ & $\chi^{2}$ & $d f$ & $p$ \\
\hline Female & .409 & .985 & 1 & .321 \\
Non-White & -1.22 & 6.17 & 1 & $.013^{*}$ \\
Age & -.897 & 8.73 & 1 & $.003^{* *}$ \\
DERS Total & .021 & 5.03 & 1 & $.025^{*}$ \\
ARS Total & -.020 & 2.32 & 1 & .128 \\
\hline Note. $* * p<.01, * p<.05$ & & & &
\end{tabular}




\section{CHAPTER IV - DISCUSSION}

The current study aimed to explore the relationships between emotion reactivity, emotion dysregulation, cognitive rumination, and NSSI frequency in a sample of at-risk adolescents. Furthermore, this study was the first of its kind to examine specific facets of emotion dysregulation as potential mediators between emotion reactivity and NSSI frequency. The NSSI prevalence rate was $18.8 \%$ in this sample of youths, which is consistent with findings in previous adolescent studies (Jacobson \& Gould 2007; Swannell, Martin, Page, Hasking, \& St. John, 2014) but lower than anticipated given previous NSSI prevalence rates at the facility used for the current study. In addition, although prior research has not found significant differences in NSSI engagement across demographic variables (Nock et al., 2006; Hilt, Nock, Lloyd-Richardson, \& Prinstein, 2008), the current sample yielded significantly higher NSSI frequency among younger individuals. This is somewhat surprising given that older individuals have had more time to engage in NSSI; however, this finding may be reflective of an underlying construct that is driving NSSI among younger individuals (e.g., impulsivity; Lockwood, Daley, Townsend, \& Sayal, 2017). Additionally, it should be noted that the sample had a restricted range of ages (i.e., 16-19 years) and that the majority of participants were on the younger end of that range; therefore, a significant relationship between age and NSSI frequency could be due to age skewness or a cohort effect.

The relationship between emotion reactivity and NSSI frequency was nonsignificant; thus, Hypothesis 1 was not supported. This finding is somewhat inconsistent with prior literature, which found that emotion reactivity was strongly related to NSSI engagement (Gratz, 2003; Gratz, 2006; Glenn et al., 2011; Nock et al., 2008). 
However, it is noteworthy that these studies examined the relationship between emotion reactivity and the presence or absence of NSSI. It is possible that emotion reactivity may be better at predicting non-NSSI and NSSI between-group differences rather than NSSIonly within-group differences; however, future studies may wish to replicate these findings among other adolescent samples before perpetuating this as an explanation.

When examining emotion reactivity and specific components of emotion dysregulation, emotion reactivity was significantly related to difficulties engaging in goal-directed behavior when dysregulated (DERS Goals), limited access to emotion regulation strategies (DERS Strategies), and difficulties controlling impulsive behavior when distressed (DERS Impulse). DERS Goals and DERS Strategies were expected (Hypotheses $2 a$ and $2 b$ ) to be significantly related to emotion reactivity, as prior literature has found associations between emotion reactivity and DERS Goals and Strategies subscales (Salsman \& Linehan, 2012). In addition, the association between emotion reactivity and DERS Impulse also emerged as significant. This makes sense given that higher levels of emotion reactivity have been linked to difficulties with self-regulation and poor inhibitory control (Billieux, Gay, Rochat, \& Van der Linden, 2010; Fabes et al., 1999; Nock et al., 2008). More specifically, Smith and Cyders (2016) recently posited that there may be a close relationship between emotion reactivity and negative urgency, a type of impulsivity in which individuals engage in rash action when experiencing negative emotions.

Interestingly, analyses in the present study did not yield the hypothesized significant differences in NSSI frequency based on distinct facets of emotion dysregulation. This finding is inconsistent with previous findings linking DERS 
Strategies and NSSI (Gratz \& Roemer, 2008; Perez et al., 2012; Turner et al., 2012) and does not support the hypothesis that DERS Strategies would be most salient in terms of NSSI frequency (Hypothesis 3). While these results may be in part due to the unique nature of the sample, a more plausible explanation may involve a methodological limitation. Specifically, in the current sample, participants who reported NSSI engagement also generally obtained higher scores across all facets of emotion dysregulation compared to those who did not report an NSSI history. A restricted range of DERS subscale scores may have created a ceiling effect in terms of predicting NSSI frequency.

As outlined in the hypotheses, rumination was expected to be significantly associated with NSSI frequency, overall emotion reactivity, and overall emotion dysregulation. Contrary to Hypothesis 4, rumination was not significantly related to NSSI frequency. This is inconsistent with prior studies that have found significant associations between rumination and NSSI among adolescents (Barrocas et al., 2015; Hilt et al., 2008; Voon et al., 2014a). It is possible that, much like DERS subscale scores, there was a ceiling effect for rumination (i.e., rumination scores were less variable within the NSSIonly sample). The current study also used a measure of anger rumination; therefore, one might reasonably argue that anger rumination does not capture other types of rumination (Peled \& Moretti, 2010) and other types of rumination would be more strongly associated with NSSI. For example, anger rumination may result in more externalizing or otherdirected harm while depressive rumination may be more predictive of self-directed harm (Anestis, Anestis, Selby, \& Joiner, 2009; du Pont, Rhee, Corley, Hewitt, \& Friedman, 2017; Peled \& Moretti, 2010). 
Rumination was significantly related to emotion reactivity (Hypothesis 5a), but not emotion dysregulation (Hypothesis 5b). Perhaps this indicates that rumination is connected to longer, more intense emotional experiences rather than how well an individual can regulate those experiences. Furthermore, it is possible that those who ruminate about their experiences may be less likely to endorse difficulties in emotion regulation if they are perceiving rumination as a positive coping mechanism. For example, Watkins and colleagues (2008) posited that rumination can be a more adaptive form of emotion regulation compared to other strategies. The authors of this study also noted that greater levels of maladaptive rumination may lead to increased emotion reactivity in response to negative stimuli. Taken together, these findings suggest that maladaptive rumination may precede heightened reactivity but not be directly related to emotion dysregulation.

The multiple mediation model that was proposed in the current study did not yield the expected findings. Specifically, none of the DERS subscales significantly mediated the relationship between emotion reactivity and NSSI frequency (Hypothesis 6). This may be in part due to a lack of power to detect meaningful effect sizes, as the sample size needed to run the proposed model could not be obtained. To address this issue, alternative models were tested using each DERS subscale as a mediator or moderator between emotion reactivity and NSSI frequency; however, none of these models were significant. Across models, emotion reactivity was a poor predictor of NSSI frequency. The weak relationship between emotion reactivity and NSSI frequency serves as a primary explanation as to why models tested in the present study were nonsignificant. One explanation for this might involve the sample being comprised mostly of males. Though 
much of the literature on sex differences in emotion reactivity has been conducted using physiological measurements (e.g., neuroimaging) rather than self-report instruments, females have consistently shown greater levels of emotion reactivity than males, particularly when exposed to negative stimuli (Stevens \& Hamann, 2012). Under this assumption, the males in the current sample do not appear to be highly emotionally reactive and other components (i.e., emotion dysregulation, rumination) seem to be better predictors of NSSI frequency.

Although emotion reactivity was unrelated NSSI frequency in this sample, an ordinal logistic regression model using DERS subscales did reveal some associations between predictors and NSSI frequency. These findings suggest that the effects of emotion dysregulation components may be additive rather than mediating or interactive. In the model that included DERS subscales, poor awareness of emotional responses (DERS Awareness) and limited access to emotion regulation strategies (DERS Strategies) uniquely predicted NSSI frequency even while controlling for demographic factors and other facets of emotion dysregulation. In a recent study, Heath and colleagues (2016) found that mindfulness (i.e., awareness) served as a protective factor against NSSI engagement. Perhaps a lack of awareness, especially awareness regarding one's emotional state, may lead to increased risk for NSSI engagement (Bresin, 2014). In terms of a lack of access to strategies, Voon, Hasking, and Martin (2014b) found that learning emotion regulation skills (e.g., cognitive reappraisal, expressive suppression) led to a decrease in NSSI in a sample of adolescents. Given that NSSI often serves as a means of regulating one's emotions (Hasking et al., 2017), it is possible NSSI is used to regulate 
emotions when individuals lack access to or the ability to use other emotion regulation techniques.

\section{Strengths and Limitations}

This study offers several strengths and contributions to the current literature on NSSI. First, the present study included a unique sample of predominantly male adolescents with self-injurious behavior. Although NSSI is often a construct studied among females (Andover, Primack, Gibb, \& Pepper, 2010), it is important to examine this phenomenon among males to determine whether meaningful sex differences are present in terms of NSSI engagement. Second, while emotion dysregulation is often studied as a unidimensional construct, research has highlighted the need to consider it as a multifaceted construct (Gratz \& Roemer, 2004). This study not only conceptualized emotion dysregulation as multidimensional, but has also tested facets of emotion dysregulation relative to one another in predicting NSSI frequency. Third, to the author's knowledge, this is the first study to test a model with both emotion reactivity and emotion dysregulation as predictors of NSSI frequency. Well-developed models of NSSI exist (Chapman, Gratz, \& Brown; Linehan, 1993; Nock \& Prinstein, 2004); however, there is still room for improvement within these models by examining how contributing factors work together to influence NSSI engagement (Hasking et al., 2017).

This study also included some methodological limitations. First, data collection was cross-sectional in nature. Therefore, no inferences could be made about temporal relationships between variables. Second, participants self-reported all information collected in this study. This method introduced potential error due to inconsistent, inaccurate, or careless responding. This is particularly important when considering NSSI 
frequency. While categorical responses options were created for the NSSI frequency item, it is still possible that participants may have over- or under-reported their histories of NSSI engagement. Third, participants were primarily homogenous in terms of gender (e.g., majority male) and ethnicity (majority White). A lack of diversity, along with the unique "at-risk" nature of the sample, has significant implications in terms of the generalizability of the findings in this study. Finally, NSSI occurred at a lower base rate than expected in the current sample. Thus, the author was unable to obtain an adequate sample size that would provide statistical power to detect smaller effect sizes.

Future Directions

Although many hypotheses in the current study were not supported, the findings offer some guidance in terms of future directions. First and foremost, findings from the current study might change if the recruitment goal was reached and the sample size had adequate statistical power for more complex analyses. Collecting data from additional participants may be necessary to detect small effect sizes. Second, it is possible that results from the current study were impacted by "ceiling effects" across independent variables. Specifically, it is possible that there was less variability among NSSI-only versus all participants in terms of the range of scores on measures of independent variables. Perhaps future analyses should test whether the relationships between emotion reactivity, emotion dysregulation, rumination, and NSSI operate differently across NSSI and non-NSSI groups. Future studies should also further investigate the role of rumination in predicting NSSI engagement. Moreover, these studies may benefit from examining alternative types of rumination (e.g., depressive rumination, ruminative worry) in addition to anger rumination. Next, emotion reactivity has been best conceptualized as 
a unidimensional construct (Nock et al., 2008). However, perhaps it functions multidimensionally depending on the sample used. Future research may focus on replicating tests of whether emotion reactivity functions as a multidimensional construct rather than unidimensional in relation to NSSI, and if so, whether certain facets of emotion reactivity more strongly related to NSSI than others. Lastly, to the author's knowledge, no studies have examined sex differences in emotion reactivity using a selfreport psychological measurement. Given that this majority-White, majority-male, nontreatment-seeking sample did not yield expected results when using the ERS to assess emotion reactivity, it may be important to test for various aspects of measurement invariance before applying the ERS to further research and practice.

\section{Conclusion}

In conclusion, the current study aimed to better understand how emotion reactivity, emotion dysregulation, and rumination are related to NSSI frequency in a sample of at-risk adolescents. Hypotheses were largely unsupported. Results could be explained by methodological factors such as low sample size, self-reported data, or crosssectional analyses. However, results could also be reflective of the unique characteristics within the sample (i.e., majority White male, non-treatment-seeking). Attempts to replicate these findings may offer utility in terms of how NSSI is conceptualized in similar adolescent samples. In addition, current empirically supported treatments for NSSI among adolescents (e.g., Dialectical Behavior Therapy-Adolescent; Rathus \& Miller, 2002) focus heavily on teaching strategies related to emotion regulation. Findings from the current study highlight the need to confirm whether addressing the same components can lead to positive outcomes among unique adolescent samples. 


\section{APPENDIX A - Emotion Reactivity Scale (ERS)}

This questionnaire asks different questions about how you experience emotions on a regular basis (for example, each day). When you are asked about being "emotional," this may refer to being angry, sad, excited, or some other emotion. Please rate the following statements.

\begin{tabular}{|c|c|c|c|c|}
\hline $\begin{array}{c}\mathbf{0} \\
\text { Not at all } \\
\text { like me }\end{array}$ & $\begin{array}{c}1 \\
\text { A little } \\
\text { like me }\end{array}$ & $\begin{array}{c}2 \\
\text { Somewhat } \\
\text { like me }\end{array}$ & $\begin{array}{c}3 \\
\text { A lot } \\
\text { like me }\end{array}$ & $\begin{array}{c}\mathbf{4} \\
\text { Completely } \\
\text { like me }\end{array}$ \\
\hline
\end{tabular}

\begin{tabular}{|l|l|c|c|c|c|c|}
\hline 1 & $\begin{array}{l}\text { When something happens that upsets me, } \\
\text { it's all I can think about it for a long time. }\end{array}$ & $\mathbf{0}$ & $\mathbf{1}$ & $\mathbf{2}$ & $\mathbf{3}$ & $\mathbf{4}$ \\
\hline 2 & My feelings get hurt easily. & $\mathbf{0}$ & $\mathbf{1}$ & $\mathbf{2}$ & $\mathbf{3}$ & $\mathbf{4}$ \\
\hline 3 & $\begin{array}{l}\text { When I experience emotions, I feel them } \\
\text { very strongly/intensely. }\end{array}$ & $\mathbf{0}$ & $\mathbf{1}$ & $\mathbf{2}$ & $\mathbf{3}$ & $\mathbf{4}$ \\
\hline 4 & $\begin{array}{l}\text { When I'm emotionally upset, my whole } \\
\text { body gets physically upset as well. }\end{array}$ & $\mathbf{0}$ & $\mathbf{1}$ & $\mathbf{2}$ & $\mathbf{3}$ & $\mathbf{4}$ \\
\hline 5 & I tend to get very emotional very easily. & $\mathbf{0}$ & $\mathbf{1}$ & $\mathbf{2}$ & $\mathbf{3}$ & $\mathbf{4}$ \\
\hline 6 & I experience emotions very strongly. & $\mathbf{0}$ & $\mathbf{1}$ & $\mathbf{2}$ & $\mathbf{3}$ & $\mathbf{4}$ \\
\hline 7 & I often feel extremely anxious. & $\mathbf{0}$ & $\mathbf{1}$ & $\mathbf{2}$ & $\mathbf{3}$ & $\mathbf{4}$ \\
\hline 8 & $\begin{array}{l}\text { When I feel emotional, it's hard for me to } \\
\text { imagine feeling any other way. }\end{array}$ & $\mathbf{0}$ & $\mathbf{1}$ & $\mathbf{2}$ & $\mathbf{3}$ & $\mathbf{4}$ \\
\hline 9 & Even the littlest things make me emotional. & $\mathbf{0}$ & $\mathbf{1}$ & $\mathbf{2}$ & $\mathbf{3}$ & $\mathbf{4}$ \\
\hline 10 & $\begin{array}{l}\text { If I have a disagreement with someone, it } \\
\text { takes a long time for me to get over it. }\end{array}$ & $\mathbf{0}$ & $\mathbf{1}$ & $\mathbf{2}$ & $\mathbf{3}$ & $\mathbf{4}$ \\
\hline 11 & $\begin{array}{l}\text { When I am angry/upset, it takes me much } \\
\text { longer than most people to calm down. }\end{array}$ & $\mathbf{0}$ & $\mathbf{1}$ & $\mathbf{2}$ & $\mathbf{3}$ & $\mathbf{4}$ \\
\hline 12 & I get angry at people very easily. & $\mathbf{0}$ & $\mathbf{1}$ & $\mathbf{2}$ & $\mathbf{3}$ & $\mathbf{4}$ \\
\hline 13 & $\begin{array}{l}\text { I am often bothered by things that other } \\
\text { people don't react to. }\end{array}$ & $\mathbf{0}$ & $\mathbf{1}$ & $\mathbf{2}$ & $\mathbf{3}$ & $\mathbf{4}$ \\
\hline 14 & I am easily agitated. & $\mathbf{0}$ & $\mathbf{1}$ & $\mathbf{2}$ & $\mathbf{3}$ & $\mathbf{4}$ \\
\hline 15 & $\begin{array}{l}\text { My emotions go from neutral to extreme in } \\
\text { an instant. }\end{array}$ & $\mathbf{0}$ & $\mathbf{1}$ & $\mathbf{2}$ & $\mathbf{3}$ & $\mathbf{4}$ \\
\hline 16 & $\begin{array}{l}\text { When something bad happens, my mood } \\
\text { changes very quickly. People tell me I have } \\
\text { a very short fuse. }\end{array}$ & $\mathbf{0}$ & $\mathbf{1}$ & $\mathbf{2}$ & $\mathbf{3}$ & $\mathbf{4}$ \\
\hline 17 & $\begin{array}{l}\text { People tell me that my emotions are often } \\
\text { too intense for the situation. }\end{array}$ & $\mathbf{0}$ & $\mathbf{1}$ & $\mathbf{2}$ & $\mathbf{3}$ & $\mathbf{4}$ \\
\hline 18 & I am a very sensitive person. & $\mathbf{0}$ & $\mathbf{1}$ & $\mathbf{2}$ & $\mathbf{3}$ & $\mathbf{4}$ \\
\hline 19 & My moods are very strong and powerful. & $\mathbf{0}$ & $\mathbf{1}$ & $\mathbf{2}$ & $\mathbf{3}$ & $\mathbf{4}$ \\
\hline 20 & $\begin{array}{l}\text { I often get so upset it's hard for me to think } \\
\text { straight. }\end{array}$ & $\mathbf{0}$ & $\mathbf{1}$ & $\mathbf{2}$ & $\mathbf{3}$ & $\mathbf{4}$ \\
\hline 21 & Other people tell me I'm overreacting. & $\mathbf{0}$ & $\mathbf{1}$ & $\mathbf{2}$ & $\mathbf{3}$ & $\mathbf{4}$ \\
\hline
\end{tabular}


APPENDIX B - Difficulties in Emotion Regulation Scale (DERS)

\section{Rate each item based upon the extent to which it is true of your experience. Please use the following scale:}

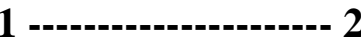

3

Never or very

rarely true

Almost always

or always true

1. I am clear about my feelings.

2. I pay attention to how I feel.

3. I experience my emotions as overwhelming and out of control.

4. I have no idea how I am feeling.

5. I have difficulty making sense out of my feelings.

6. I am attentive to my feelings.

7. I know exactly how I am feeling.

8. I care about what I am feeling.

9. I am confused about how I feel.

10. When I'm upset, I acknowledge my emotions.

11. When I'm upset, I become angry with myself for feeling that way.

12. When I'm upset, I become embarrassed for feeling that way.

13. When I'm upset, I have difficulty getting work done.

14. When I'm upset, I become out of control.

15. When I'm upset, I believe that I will remain that way for a long time.

16. When I'm upset, I believe that I'll end up feeling very depressed.

17. When I'm upset, I believe that my feelings are valid and important.

18. When I'm upset, I have difficulty focusing on other things.

19. When I'm upset, I feel out of control.

20. When I'm upset, I can still get things done.

21. When I'm upset, I feel ashamed with myself for feeling that way.

22. When I'm upset, I know that I can find a way to eventually feel better.

23. When I'm upset, I feel like I am weak.

24. When I'm upset, I feel like I can remain in control of my behaviors.

25 . When I'm upset, I feel guilty for feeling that way.

26. When I'm upset, I have difficulty concentrating.

27. When I'm upset, I have difficulty controlling my behaviors.

28. When I'm upset, I believe there is nothing I can do to make myself feel better.

29. When I'm upset, I become irritated with myself for feeling that way.

30. When I'm upset, I start to feel very bad about myself.

31. When I'm upset, I believe that wallowing in it is all I can do.

32. When I'm upset, I lose control over my behaviors.

33. When I'm upset, I have difficulty thinking about anything else.

34. When I'm upset, I take time to figure out what I'm really feeling.

35 . When I'm upset, it takes me a long time to feel better.

36. When I'm upset, my emotions feel overwhelming. 


\section{APPENDIX C - Anger Rumination Scale (ARS)}

Sukhodolsky, D. G., Golub, A., \& Cromwell, E. N. (2001). Development and validation of the anger rumination scale. Personality and Individual Differences, 31(5), 689-700. https://doi.org/10.1016/S0191-8869(00)00171-9

"Angry Afterthoughts"

14 I re-enact the anger episode in my mind after it has happened

19 When something makes me angry, I turn this matter over and over again in my mind

18 Memories of even minor annoyances bother me for a while

9 Whenever I experience anger, I keep thinking about it for a while

7 After an argument is over, I keep fighting with this person in my imagination

8 Memories of being aggravated pop up into my mind before I fall asleep

"Thoughts of Revenge"

4 I have long living fantasies of revenge after the conflict is over

16 When someone makes me angry I can't stop thinking about how to get back at this person

13 I have day dreams and fantasies of violent nature

6 I have difficulty forgiving people who have hurt me

\section{"Angry Memories"}

2 I ponder about the injustices that have been done to me

3 I keep thinking about events that angered me for a long time

15 I feel angry about certain things in my life

1 I ruminate about my past anger experiences

5 I think about certain events from a long time ago and they still make me angry

"Understanding of Causes"

12 I think about the reasons people treat me badly

17 When someone provokes me, I keep wondering why this should have happened to me

11 I analyze events that make me angry

10 I have had times when I could not stop being preoccupied with a particular conflict 
INSTRUCTIONS: Please read each question carefully and respond as accurately as you can. Please be sure to pay attention to the instructions for skipping certain items.

1) Have you ever had thoughts of killing yourself?

(Circle your response)

IF YES, PLEASE CONTINUE BELOW. YES NO

IF NO, PLEASE CONTINUE AT QUESTION 10.

How old were you the first time you had thoughts of killing

2) yourself?

How old were you the last time you had thoughts of killing

3) yourself?

How many days in your life have you had thoughts of killing

4) yourself?

How many days in the past year have you had thoughts of

5) killing yourself?

How many days in the past month have you had thoughts of

6) killing yourself?

How many days in the past week have you had thoughts of

7) killing yourself?

At the worst point, how intense were your thoughts of

8) killing yourself?

Low/ Very much/

Little Severe

On average, how intense were your thoughts of killing

9) yourself?

$\begin{array}{lllll}0 & 1 & 2 & 3 & 4\end{array}$

$\begin{array}{lllll}0 & 1 & 2 & 3 & 4\end{array}$

10) What do you think the likelihood is that you will have thoughts of killing yourself in the future?

$\begin{array}{lllll}0 & 1 & 2 & 3 & 4\end{array}$

PLEASE CONTINUE ON THE NEXT PAGE 
11) Have you ever actually made a plan to kill yourself?

(Circle your response)

IF YES, PLEASE CONTINUE BELOW.

IF NO, PLEASE CONTINUE AT QUESTION

20.

12) How old were you the first time you made a suicide plan?

13) How old were you the last time you made a suicide plan?

14) How many days in your life have you made a suicide plan?

How many days in the past year have you made a suicide

15) plan?

How many days in the past month have you made a suicide

16) plan?

How many days in the past week have you made a suicide

17) plan?

At the worst point, how seriously did you consider

18) acting on the plan?

On average, how seriously did you consider acting on

19) the plan(s)?

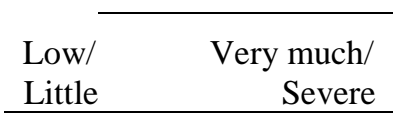

$\begin{array}{lllll}0 & 1 & 2 & 3 & 4\end{array}$

$\begin{array}{lllll}0 & 1 & 2 & 3 & 4\end{array}$

20) What do you think the likelihood is that you will make a suicide plan in the future?

$\begin{array}{lllll}0 & 1 & 2 & 3 & 4\end{array}$

\section{PLEASE CONTINUE ON THE NEXT PAGE}


21) Have you ever made a suicide gesture (that is, done something to lead someone to believe that you wanted to kill yourself when you really had no intention of doing so)?

(Circle your response)

IF YES, PLEASE CONTINUE BELOW.

IF NO, PLEASE CONTINUE AT QUESTION

28.

How old were you the first time you made a suicide 22) gesture?

How old were you the last time you made a suicide 23) gesture?

How many times in your life have you made a suicide 24) gesture?

How many times in the past year have you made a suicide 25) gesture?

How many times in the past month have you made a 26) suicide gesture?

How many times in the past week have you made a 27) suicide gesture?

Low/ Very much/

Little Severe

28) What do you think the likelihood is that you will make a suicide gesture in the future?

$\begin{array}{lllll}0 & 1 & 2 & 3 & 4\end{array}$

\section{PLEASE CONTINUE ON THE NEXT PAGE}


29) Have you ever made an actual attempt to kill yourself in which you had at least some intent to

die?

(Circle your response)

IF YES, PLEASE CONTINUE BELOW.

YES NO

IF NO, PLEASE CONTINUE AT QUESTION

38.

30) How old were you the first time you made a suicide attempt?

31) When was the most recent suicide attempt?

32) How many suicide attempts have you made in your lifetime?

33) How many suicide attempts have you made in the past year?

34) How many suicide attempts have you made in the past month?

35) How many suicide attempts have you made in the past week?

What method did you use for your most severe suicide

36) attempt?

37) How many times in your life did you receive medical treatment for a suicide attempt (such as stitches or surgery)?

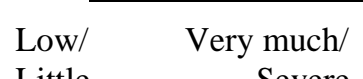

Little Severe

38) What do you think the likelihood is that you will make a suicide attempt in the future?

$\begin{array}{lllll}0 & 1 & 2 & 3 & 4\end{array}$

\section{PLEASE CONTINUE ON THE NEXT PAGE}


39) Have you ever had thoughts of non-suicidal selfinjury (NSSI; that is, thoughts of purposely hurting yourself without wanting to die, for example thoughts of cutting or burning)?

(Circle your response)

IF YES, PLEASE CONTINUE BELOW.

YES

\section{IF NO, PLEASE CONTINUE AT QUESTION}

48.

How old were you the first time you had thoughts of non-

40) suicidal self-injury (NSSI)?

41) How old were you the last time you had thoughts of NSSI?

42) How many days in your life have you had thoughts of NSSI?

How many days in the past year have you had thoughts of

43) NSSI?

How many days in the past month have you had thoughts of

44) NSSI?

How many days in the past week have you had thoughts of

45) NSSI?

$\begin{array}{lr}\text { Low/ } & \text { Very much/ } \\ \text { Little } & \text { Severe }\end{array}$

At the worst point, how intense were your thoughts of

46) NSSI?

$\begin{array}{lllll}0 & 1 & 2 & 3 & 4\end{array}$

47) On average, how intense were your thoughts of NSSI? $\quad \begin{array}{lllllll}0 & 1 & 2 & 3 & 4\end{array}$

48) What do you think the likelihood is that you will have thoughts of NSSI in the future?

$\begin{array}{lllll}0 & 1 & 2 & 3 & 4\end{array}$

\section{PLEASE CONTINUE ON THE NEXT PAGE}


49) Have you ever actually engaged in non-suicidal selfinjury (NSSI; that is, purposely hurt yourself without wanting to die, for example by cutting or burning)?

(Circle your response)

IF YES, PLEASE CONTINUE BELOW.

IF NO, PLEASE CONTINUE AT QUESTION 58.

50) How old were you the first time you engaged in NSSI?

51) How old were you the last time you engaged in NSSI?

52) How many times in your life have you engaged in NSSI?

53) How many times in the past year have you engaged in NSSI?

54) How many times in the past month have you engaged in NSSI?

55) How many times in the past week have you engaged in NSSI?

56) Here is a list of things that people have done to harm themselves.

Please circle YES or NO to indicate whether you have engaged in these behaviors
a. Cut or carved skin
YES
NO
b. Hit yourself on purpose resulting in bruising
YES
NO
c. Picked areas of your body to the point of draw
YES
NO
d. Burned your skin (with a cigarette, match, or o object)
YES
NO
e. Inserted sharp objects into your nails or skin
YES
NO
f. Scraped your skin to the point of drawing bloo
YES
NO
g. Other (please specify):
YES
NO

57) Have you ever received medical treatment for

YES

NO injuries caused by NSSI?

\begin{tabular}{|llllll|}
\multicolumn{1}{|l}{$\begin{array}{l}\text { 58) What do you think the likelihood is that you will engage } \\
\text { in NSSI in the future? }\end{array}$} & $\begin{array}{c}\text { Low/ } \\
\text { Little }\end{array}$ & $\begin{array}{r}\text { Very Much/ } \\
\text { Severe }\end{array}$ \\
\hline
\end{tabular}

END OF QUESTIONNAIRE 


\section{APPENDIX E - IRB Approval Letter}

\section{fir \\ (1) THE UNIVERSITY OF INIIII SOUTHERN MISSISSIPPI.}

INSTITUTIONAL REVIEW BOARD

118 College Drive \#5147 | Hattiesburg, MS 39406-0001

Phone: 601.266 .5997 | Fax: 601.266 .4377 | www.usm.edu/research/institutional.review.board

\section{NOTICE OF COMMITTEE ACTION}

The project has been reviewed by The University of Southern Mississippi Institutional Review Board in accordance with Federal Drug Administration regulations (21 CFR 26, 111), Department of Health and Human Services (45 CFR Part 46), and university guidelines to ensure adherence to the following criteria:

- The risks to subjects are minimized.

- The risks to subjects are reasonable in relation to the anticipated benefits.

- The selection of subjects is equitable.

- Informed consent is adequate and appropriately documented

- Where appropriate, the research plan makes adequate provisions for monitoring the data collected to ensure the safety of the subjects.

- Where appropriate, there are adequate provisions to protect the privacy of subjects and to maintain the confidentiality of all data.

- Appropriate additional safeguards have been included to protect vulnerable subjects.

- Any unanticipated, serious, or continuing problems encountered regarding risks to subjects must be reported immediately, but not later than 10 days following the event. This should be reported to the IRB Office via the "Adverse Effect Report Form".

- If approved, the maximum period of approval is limited to twelve months.

Projects that exceed this period must submit an application for renewal or continuation.

PROTOCOL NUMBER: CH10-24111802

PROJECT TITLE: Predictors of Behavioral Outcomes in a Group of At-Risk Adolescents (Change in procedure)

PROJECT TYPE: Change \#10 to a Previously Approved Project

RESEARCHER(S): Nora Charles, Ph.D.

COLLEGE/DIVISION: College of Education \& Psychology

DEPARTMENT: Psychology

FUNDING AGENCY/SPONSOR: N/A

IRB COMMITTEE ACTION: Expedited Review Approval

PERIOD OF APPROVAL: 08/25/2017 to 08/24/2018

Lawrence A. Hosman, Ph.D.

Institutional Review Board 


\section{REFERENCES}

Adrian, M., Zeman, J., Erdley, C., \& Lisa, L., \& Sim, L. (2011). Emotion dysregulation and interpersonal difficulties as risk factors for nonsuicidal self-injury in adolescent girls. Journal of Abnormal Child Psychology, 39(3), 389-400. https://doi.org/10.1007/s10802-010-9465-3

American Psychiatric Association. (2013). Diagnostic and statistical manual of mental disorders (5th ed.). Arlington, VA: American Psychiatric Publishing.

Anderson, N. L., \& Crowther, J. H. (2012). Using the experiential avoidance model of non-suicidal self-injury: Understanding who stops and who continues. Archives of Suicide Research, 16(2), 124-134.

http://dx.doi.org/10.1080/13811118.2012.667329

Andover, M. S., Primack, J. M., Gibb, B. E., \& Pepper, C. M. (2010). An examination of non-suicidal self-injury in men: do men differ from women in basic NSSI characteristics?. Archives of Suicide Research, 14(1), 79-88.

https://doi.org/10.1080/13811110903479086

Andrews, T., Martin, G., Hasking, P., \& Page, A. (2014). Predictors of onset for nonsuicidal self-injury within a school-based sample of adolescents. Prevention Science, 15(6), 850-859. doi:10.1007/s11121-013-0412-8

Anestis, M. D., Anestis, J. C., Selby, E. A., \& Joiner, T. E. (2009). Anger rumination across forms of aggression. Personality and Individual Differences, 46(2), 192196. https://doi.org/10.1016/j.paid.2008.09.026

Anestis, M. D., Khazem, L. R., \& Law, K. C. (2015). How many times and how many ways: The impact of number of nonsuicidal self-injury methods on the 
relationship between nonsuicidal self-injury frequency and suicidal behavior. Suicidal and Life-Threatening Behavior, 45(2), 164-177. doi:10.1111/sltb.12120

Arbuthnott, A. E., Lewis, S. P., \& Bailey, H. N. (2015). Rumination and emotions in nonsuicidal self-injury and eating disorder behaviors: A preliminary test of the emotional cascade model. Journal of Clinical Psychology, 71(1), 62-71. https://doi.org/10.1002/jclp.22115

Barrocas, A. L., Giletta, M., Hankin, B. L., Prinstein, M. J., \& Abela, J. R. (2015). Nonsuicidal self-injury in adolescence: Longitudinal course, trajectories, and intrapersonal predictors. Journal of Abnormal Child Psychology, 43(2), 369-380. https://doi.org/10.1007/s10802-014-9895-4

Billeaux, J., Gay, P., Rochat, L., \& Van der Linden, M. (2010). The role of urgency and its underlying psychological mechanisms in problematic behaviours. Behaviour Research and Therapy, 48(11), 1085-1096. https://doi.org/10.1016/j.brat.2010.07.008

Brausch, A. M., \& Gutierrez, P. M. (2010). Differences in non-suicidal self-injury and suicide attempts in adolescents. Journal of Youth and Adolescence, 39(3), 233242. https://doi.org/10.1007/s10964-009-9482-0

Bresin, K. (2014). Five indices of emotion regulation in participants with a history of nonsuicidal self-injury: A daily diary study. Behavior Therapy, 45(1), 56-66. https://doi.org/10.1016/j.beth.2013.09.005

Bresin, K., \& Gordon, K. H. (2013). Changes in negative affect following pain (vs. nonpainful) stimulation in individuals with and without a history of nonsuicidal 
self-injury. Personality Disorders: Theory, Research, and Treatment, 4(1), 62-66. http://dx.doi.org/10.1037/a0025736

Bresin, K., Gordon, K. H., Bender, T. W., Gordon, L. J., \& Joiner, T. E., Jr. (2010). No pain, no change: Reductions in prior negative affect following physical pain. Motivation and Emotion, 34(3), 280-287. https://doi.org/10.1007/s11031-0109168-7

Briere, J., \& Gil, E. (1998). Self-mutilation in clinical and general population samples: Prevalence, correlates, and functions. American Journal of Orthopsychiatry, 68(4), 609-620. doi:10.1037/h0080369

Brunner, R., Parzer, P., Haffner, J., Steen, R., Roos, J., Klett, M., \& Resch, F. (2007). Prevalence and psychological correlates of occasional and repetitive deliberate self-harm in adolescents. Archives of Pediatrics \& Adolescent Medicine, 161(7), 641-649.

Chapman, A. L., Gratz, K. L., \& Brown, M. Z. (2006). Solving the puzzle of deliberate self-harm: The experiential avoidance model. Behaviour Research and Therapy, 44(3), 371-394. https://doi.org/10.1016/j.brat.2005.03.005

Cohen, J. (1992). A power primer. Psychological Bulletin, 112(1), 155-159. http://dx.doi.org/10.1037/0033-2909.112.1.155

Cox, L. J., Stanley, B. H., Melhem, N. M., Oquendo, M. A., Birmaher, B., Burke, A., Kolko, D. J., Zelazny, J. M., Mann, J. J., Porta, G., \& Brent, D. A. (2012). A longitudinal study of nonsuicidal self-injury in offspring at high risk for mood disorder. Journal of Clinical Psychiatry, 73(6), 821-828. doi:10.4088/JCP.11m07250 
Donaldson, C., \& Lam, D. (2004). Rumination, mood and social problem-solving in major depression. Psychological Medicine, 34(7), 1309-1318. https://doi.org/10.1017/S0033291704001904

du Pont, A., Rhee, S. H., Corley, R. P., Hewitt, J. K., \& Friedman, N. P. (2018). Rumination and Psychopathology: Are Anger and Depressive Rumination Differentially Associated With Internalizing and Externalizing Psychopathology?. Clinical Psychological Science, 6(1), 18-31. https://doi.org/10.1177/2167702617720747

Fabes, R. A., Eisenberg, N., Jones, S., Smith, M., Guthrie, I., Poulin, R., ... \& Friedman, J. (1999). Regulation, emotionality, and preschoolers' socially competent peer interactions. Child Development, 70(2), 432-442. https://doi.org/10.1111/14678624.00031

Favazza, A. R. (2015). Nonsuicidal self-injury: How categorization guides treatment. Current Psychiatry, 11(3), 21-26.

Franklin, J. C., Aaron, R. V., Arthur, M. S., Shorkey, S. P., \& Prinstein, M. J. (2012). Nonsuicidal self-injury and diminished pain perception: The role of emotion dysregulation. Comprehensive Psychiatry, 53(6), 691-700. https://doi.org/10.1016/j.comppsych.2011.11.008

Franklin, J. C., Hessel, E. T., Aaron, R. V., Arthur, M. S., Heilbron, N., \& Prinstein, M. J. (2010). The functions of nonsuicidal self-injury: Support for cognitive-affective regulation and opponent processes from a novel psychophysiological paradigm. Journal of Abnormal Psychology, 119(4), 850-862.

http://dx.doi.org/10.1037/a0020896 
Franklin, J. C., \& Nock, M. K. (2016). Nonsuicidal self-injury and its relation to suicidal behavior. In P. M. Kleespies (Ed.), The Oxford Handbook of Behavioral Emergencies and Crises (pp. 401-416). New York, NY: Oxford University Press.

Garnefski, N., Kraaij, V., \& Spinhoven, P. (2001). Negative life events, cognitive emotion regulation and emotional problems. Personality and Individual differences, 30(8), 1311-1327. https://doi.org/10.1016/S0191-8869(00)00113-6

Garnefski, N., Kraaij, V., \& Spinhoven, P. (2002). Manual for the use of the Cognitive Emotion Regulation Questionnaire. Leiderdorp, The Netherlands: DATEC.

Glenn, C. R., Blumenthal, T. D., Klonsky, E. D., \& Hajcak, G. (2011). Emotional reactivity in nonsuicidal self-injury: Divergence between self-report and startle measures. International Journal of Psychophysiology, 80(2), 166-170. https://doi.org/10.1016/j.ijpsycho.2011.02.016

Glenn, C. R., \& Klonsky, E. D. (2011). Prospective prediction of nonsuicidal self-injury: A 1-year longitudinal study in young adults. Behavioral Therapy, 42(4), 751-762. doi:10.1016/j.beth.2011.04.005

Gollust, S. E., Eisenberg, D., \& Golberstein, E. (2008). Prevalence and correlates of selfinjury among university students. Journal of American College Health, 56(5), 491-498. http://dx.doi.org/10.3200/JACH.56.5.491-498

Gratz, K. L. (2003). Risk factors for and functions of deliberate self-harm: An empirical and conceptual review. Clinical Psychology: Science and Practice, 10(2), 192205. doi:10.1093/clipsy.bpg022

Gratz, K. L. (2006). Risk factors for deliberate self-harm among female college students: The role and interaction of childhood maltreatment, emotional inexpressivity, and 
affect intensity/reactivity. American Journal of Orthopsychiatry, 76(2), 238-250. http://dx.doi.org/10.1037/0002-9432.76.2.238

Gratz, K. L., Conrad, S. D., \& Roemer, L. (2002). Risk factors for deliberate self-harm among college students. American Journal of Orthopsychiatry, 72(1), 128-140. http://dx.doi.org/10.1037/0002-9432.72.1.128

Gratz, K. L., \& Roemer, L. (2004). Multidimensional assessment of emotion regulation and dysregulation: Develop, factor structure, and initial validation of the Difficulties in Emotion Regulation Scale. Journal of Psychopathology and Behavioral Assessment, 26(1), 41-54.

https://doi.org/10.1023/B:JOBA.0000007455.08539.94

Gratz, K. L., \& Tull, M. T. (2010). The relationship between emotion dysregulation and deliberate self-harm among inpatients with substance use disorders. Cognitive Therapy Research, 34(6), 544-553. doi:10.1007/s10608-009-9268-4

Green, S. B. (1991). How many subjects does it take to do a regression analysis. Multivariate Behavioral Research, 26(3), 499-510. http://dx.doi.org/10.1207/s15327906mbr2603_7

Hankin, B.L., \& Abela, J. R. Z. (2011). Nonsuicidal self-injury in adolescence: Prospective rates and risk factors in a 21/2 year longitudinal study. Psychiatric Research, 186(1), 65-70. doi:10.1016/j.psychres.2010.07.056

Hasking, P., Whitlock, J., Voon, D., \& Rose, A. (2017). A cognitive-emotional model of NSSI: Using emotion regulation and cognitive processes to explain why people self-injure. Cognition and Emotion, 31(8), 1543-1556. https://doi.org/10.1080/02699931.2016.1241219 
Heath, N. L., Carsley, D., De Riggi, M. E., Mills, D., \& Mettler, J. (2016). The relationship between mindfulness, depressive symptoms, and non-suicidal selfinjury amongst adolescents. Archives of Suicide Research, 20(4), 635-649. https://doi.org/10.1080/13811118.2016.1162243

Heath, N., Toste, J., Nedecheva, T., \& Charlebois, A. (2008). An examination of nonsuicidal self-injury among college students. Journal of Mental Health Counseling, 30(2), 137-156. https://doi.org/10.17744/mehc.30.2.8p879p3443514678

Hilt, L. M., Cha, C. B., \& Nolen-Hoeksema, S. (2008). Nonsuicidal self-injury in young adolescent girls: Moderators of the distress-function relationship. Journal of Consulting and Clinical Psychology, 76(1), 63-71. http://dx.doi.org/10.1037/0022-006X.76.1.63

Hilt, L. M., Nock, M. K., Lloyd-Richardson, E. E., \& Prinstein, M. J. (2008). Longitudinal study of nonsuicidal self-injury among young adolescents: Rates, correlates, and preliminary test of an interpersonal model. Journal of Early Adolescence, 28(3), 455-469. https://doi.org/10.1177/0272431608316604

Hoff, E. R., \& Muehlenkamp, J. J. (2009). Nonsuicidal self-injury in college students: The role of perfectionism and rumination. Suicide and Life-Threatening Behavior, 39(6), 576-587. https://doi.org/10.1521/suli.2009.39.6.576

Howe-Martin, L. S., Murrell, A. R., \& Guarnaccia, C. A. (2012). Repetitive nonsuicidal self-injury as experiential avoidance among a community sample of adolescents. Journal of Clinical Psychology, 68(7), 809-829. doi:10.1002/jclp.21868 
IBM Corporation. (2015). IBM SPSS Statistics for Windows, Version 23.0. Armonk, NY: IBM Corporation.

Jacobson, C. M., \& Gould, M. (2007). The epidemiology and phenomenology of nonsuicidal self-injurious behavior among adolescents: A critical review of the literature. Archives of Suicide Research, 11(2), 129-147.

http://dx.doi.org/10.1080/13811110701247602

Kapur, N., Cooper, J., O’Connor, R. C., \& Hawton, K. (2013). Non-suicidal self-injury v. attempted suicide: New diagnosis or false dichotomy? The British Journal of Psychiatry, 202(5), 326-328. doi:10.1192/bjp.bp.112.116111

Karrass, J., Walden, T. A., Conture, E. G., Graham, C. G., Arnold, H. S., Hartfield, K. N., \& Schwenk, K. A. (2006). Regulation of emotional reactivity and regulation to childhood stuttering. Journal of Communication Disorders, 39(6), 402-423. doi:10.1016/j.jcomdis.2005.12.004

Klonsky, E. D. (2007). The functions of deliberate self-injury: A review of the evidence. Clinical Psychology Review, 27(2), 226-239. https://doi.org/10.1016/j.cpr.2006.08.002

Klonsky, E. D. (2011). Non-suicidal self-injury in United States adults: Prevalence, sociodemographics, topography and functions. Psychological Medicine, 41(9), 1981-1986. https://doi.org/10.1017/S0033291710002497

Klonsky, E. D., \& Glenn, C. R. (2009). Assessing the functions of non-suicidal selfinjury: Psychometric properties of the inventory of statements about self-injury (ISAS). Journal of Psychopathology and Behavioral Assessment, 31(XX), 215219. 
doi:10.1007/s10862-008-9107-z

Klonsky, E. D., \& Olino, T. M. (2008). Identifying clinically distinct subgroups of selfinjurers among young adults: A latent class analysis. Journal of Consulting and Clinical Psychology, 76(1), 22-27. doi:10.1037/0022-006X.76.1.22

Kumar, G., Pepe, D., \& Steer, R. A. (2004). Adolescent psychiatric inpatients'selfreported reasons for cutting themselves. Journal of Nervous \& Mental Disease, 192(12), 830-836.

Lavender, A., \& Watkins, E. (2004). Rumination and future thinking in depression. British Journal of Clinical Psychology, 43(2), 129-142. https://doi.org/10.1348/014466504323088015

Laye-Gindhu, A., \& Schonert-Reichl, K. A. (2005). Nonsuicidal self-harm among community adolescents: Understanding the "whats" and "whys" of self-harm. Journal of Youth and Adolescence, 34(5), 447-457. doi:10.1007/s10964-005$7262-\mathrm{z}$

Linehan, M. M. (1993). Cognitive-behavioral therapy of borderline personality disorder. New York: Guilford Press.

Lloyd-Richardson, E. E., Perrine, N., Dierker, L., \& Kelley, M. E. (2007). Characteristics and functions of non-suicidal self-injury in a community sample of adolescents. Psychological Medicine, 37(8), 1183-1192. doi:10.1017/S003329170700027X

Lockwood, J., Daley, D., Townsend, E., \& Sayal, K. (2017). Impulsivity and self-harm in adolescence: a systematic review. European Child \& Adolescent Psychiatry, 26(4), 387-402. https://doi.org/10.1007/s00787-016-0915-5 
MacLaren, V. V., \& Best, L. A. (2010). Nonsuicidal self-injury, potentially addictive behaviors, and the Five Factor Model in undergraduates. Personality and Individual Differences, 49(5), 521-525. https://doi.org/10.1016/j.paid.2010.05.019

Marshall, S. K., Tilton-Weaver, L. C., \& Stattin, H. (2013). Non-suicidal self-injury and depressive symptoms during middle adolescence: A longitudinal analysis. Journal of Youth and Adolescence, 42(8), 1234-1242. doi:10.1007/s10964-013-9919-3

Mennin, D. S., Holaway, R. M., Fresco, D. M., Moore, M. T., \& Heimberg, R. G. (2007). Delineating components of emotion and its dysregulation in anxiety and mood psychopathology. Behavior Therapy, 38(3), 284-302. https://doi.org/10.1016/j.beth.2006.09.001

Muehlenkamp, J. J., \& Gutierrez, P. M. (2004). An investigation of differences between self-injurious behavior and suicide attempts in a sample of adolescents. Suicide and Life-Threatening Behavior, 34(1), 12-23.

Muehlenkamp, J. J., Walsh, B. W., \& McDade, M. (2010). Preventing non-suicidal selfinjury in adolescents: The signs of self-injury program. Journal of Youth and Adolescence, 39(3), 306-314. https://doi.org/10.1007/s10964-009-9450-8

Nicolai, K. A., Wielgus, M. D., \& Mezulis, A. (2016). Identifying risk for self-harm: Rumination and negative affectivity in the prospective prediction of nonsuicidal self-injury. Suicide and Life-Threatening Behavior, 46(2), 223-233. https://doi.org/10.1111/sltb.12186

Nitkowski, D., \& Petermann, F. (2011). Non-suicidal self-injury and comorbid mental disorders: A review. Fortschritte der Neurologie-Psychiatrie, 79(1), 9-20. doi: $10.1055 / \mathrm{s}-0029-1245772$ 
Nixon, M. K., Cloutier, P. F., \& Aggarwal, S. (2002). Affect regulation and addictive aspects of repetitive self-injury in hospitalized adolescents. Journal of the American Academy of Child \& Adolescent Psychiatry, 41(11), 1333-1341. https://doi.org/10.1097/00004583-200211000-00015

Nixon, M. K., Cloutier, P., \& Jansson, S. M. (2008). Nonsuicidal self-harm in youth: A population-based survey. Canadian Medical Association Journal, 178(3), 306312. doi:10.1503/cmaj.061693

Nock, M. K. (2009). Why do people hurt themselves? New insights into the nature and functions of self-injury. Current Directions in Psychological Science, 18(2), 7883. https://doi.org/10.1111/j.1467-8721.2009.01613.x

Nock, M. K., \& Favazza, A. R. (2009). Nonsuicidal self-injury: Definition and classification. In M. K. Nock (Ed.), Understanding Nonsuicidal Self-Injury: Origins, Assessment, and Treatment. Washington, DC: American Psychological Association.

Nock, M. K., Holmberg, E. B., Photos, V. I., \& Michel, B. D. (2007). Self-Injurious Thoughts and Behaviors Interview: Development, reliability, and validity in an adolescent sample. Psychological Assessment, 19(3), 309-317. doi:10.1037/10403590.19.3.309

Nock, M. K., Joiner, T. E., Jr., Gordon, K. H., Lloyd-Richardson, E., \& Prinstein, M. J. (2006). Non-suicidal self-injury among adolescents: Diagnostic correlates and relation to suicide attempts. Psychiatry Research, 144(1), 65-72. doi:10.1016/j.psychres.2006.05.010 
Nock, M. K., \& Mendes, W. B. (2008). Physiological arousal, distress tolerance, and social problem-solving deficits among adolescent self-injurers. Journal of Consulting and Clinical Psychology, 76(1), 28-38. doi:10.1037/0022006X.76.1.28

Nock, M. K., \& Prinstein, M. J. (2004). A functional approach to the assessment of selfmutilative behavior. Journal of Consulting and Clinical Psychology, 72(5), 885890. doi:10.1037/0022-006X.72.5.885

Nock, M. K., Wedig, M. M., Holmberg, E. B., \& Hooley, J. M. (2008). The Emotion Reactivity Scale: Development, evaluation, and relation to self-injurious thoughts and behaviors. Behavior Therapy, 39(2), 107-116.

https://doi.org/10.1016/j.beth.2007.05.005

Nolen-Hoeksema, S. (1991). Responses to depression and their effects on the duration of depressive episodes. Journal of Abnormal Psychology, 100(4), 569-582. http://dx.doi.org/10.1037/0021-843X.100.4.569

Nolen-Hoeksema, S., Wisco, B. E., \& Lyubomirsky, S. (2008). Rethinking rumination. Perspectives on Psychological Science, 3(5), 400-424. https://doi.org/10.1111/j.1745-6924.2008.00088.x

Peled, M., \& Moretti, M. M. (2010). Ruminating on rumination: Are rumination on anger and sadness differentially related to aggression and depressed mood?. Journal of Psychopathology and Behavioral Assessment, 32(1), 108-117. https://doi.org/10.1007/s10862-009-9136-2

Penn, J. V., Esposito, C. L., Schaeffer, L. E., Fritz, G. K., \& Spirito, A. (2003). Suicide attempts and self-mutilative behavior in a juvenile correctional facility. Journal of 
the American Academy of Child \& Adolescent Psychiatry, 42(7), 762-769. https://doi.org/10.1097/01.CHI.0000046869.56865.46

Perez, J., Venta, A., Garnaat, S., \& Sharp, C. (2012). The Difficulties in Emotion Regulation Scale: Factor structure and association with nonsuicidal self-injury in adolescent inpatients. Journal of Psychopathology and Behavioral Assessment, 34(3), 393-404. https://doi.org/10.1007/s10862-012-9292-7

Preacher, K. J., \& Hayes, A. F. (2004). SPSS and SAS procedures for estimating indirect effects in simple mediation models. Behavior Research Methods, Instruments, and Computers, 36(4), 717-731. https://doi.org/10.3758/BF03206553

Preacher, K. J., \& Hayes, A. F. (2008). Asymptotic and resampling strategies for assessing and comparing indirect effects in multiple mediator models. Behavior Research Methods, 40(3), 879-891. https://doi.org/10.3758/BRM.40.3.879

Prinstein, M. J., Heilbron, N., Guerry, J. D., Franklin, J. C., Rancourt, D., Simon, V., \& Spirito, A. (2010). Peer influence and nonsuicidal self injury: Longitudinal results in community and clinically-referred adolescent samples. Journal of Abnormal Child Psychology, 38(5), 669-682. doi:10.1007/s10802-010-9423-0

Qualtrics. (2017). Qualtrics. Provo, UT: Qualtrics.

Rathus, J. H., \& Miller, A. L. (2002). Dialectical behavior therapy adapted for suicidal adolescents. Suicide and Life-Threatening Behavior, 32(2), 146-157. https://doi.org/10.1521/suli.32.2.146.24399

Ray, R. D., Wilhelm, F. H., \& Gross, J. J. (2008). All in the mind's eye? Anger rumination and reappraisal. Journal of Personality and Social Psychology, 94(1), 133-145. doi: 10.1037/0022-3514.94.1.133 
Richmond, S., Hasking, P., \& Meaney, R. (2017). Psychological distress and non-suicidal self-injury: The mediating roles of rumination, cognitive reappraisal, and expressive suppression. Archives of Suicide Research, 21(1), 62-72. https://doi.org/10.1080/13811118.2015.1008160

Rusting, C. L., \& Nolen-Hoeksema, S. (1998). Regulating responses to anger: Effects of rumination and distraction on angry mood. Journal of Personality and Social Psychology, 74(3), 790-803. http://dx.doi.org/10.1037/0022-3514.74.3.790

Salsman, N. L., \& Linehan, M. M. (2012). An investigation of relationships among negative affect, difficulties in emotion regulation, and features of borderline personality disorder. Journal of Psychopathology and Behavioral Assessment, 34(2), 260-267. doi:10.1007/s10862-012-9275-8

Selby, E. A., Anestis, M. D., \& Joiner, T. E. (2008). Understanding the relationship between emotional and behavioral dysregulation: Emotional cascades. Behaviour research and therapy, 46(5), 593-611. https://doi.org/10.1016/j.brat.2008.02.002

Selby, E. A., Bender, T. W., Gordon, K. H., Nock, M. K., \& Joiner, T. E., Jr. (2011). Non-suicidal self-injury (NSSI) disorder: A preliminary study. Personality Disorders: Theory, Research, and Treatment, 3(2), 167-175. doi:10.1037/a002440

Selby, E. A., Franklin, J., Carson-Wong, A., \& Rizvi, S. L. (2013). Emotional cascades and self-injury: Investigating instability of rumination and negative emotion. Journal of Clinical Psychology, 69(12), 1213-1227. doi:10.1002/jclp.21966 
Smith, G. T., \& Cyders, M. A. (2016). Integrating affect and impulsivity: The role of positive and negative urgency in substance use risk. Drug and Alcohol Dependence, 163(1), S3-S12. https://doi.org/10.1016/j.drugalcdep.2015.08.038

Stevens, J. S., \& Hamann, S. (2012). Sex differences in brain activation to emotional stimuli: a meta-analysis of neuroimaging studies. Neuropsychologia, 50(7), 15781593. https://doi.org/10.1016/j.neuropsychologia.2012.03.011

St. Germain, S. A., Hooley, J. M. (2012). Direct and indirect forms of non-suicidal selfinjury: Evidence for a distinction. Psychiatry Research, 197(1-2), 78-84. https://doi.org/10.1016/j.psychres.2011.12.050

Sukhodolsky, D. G., Golub, A., \& Cromwell, E. N. (2001). Development and validation of the Anger Rumination Scale. Personality and Individual Differences, 31(5), 689-700. https://doi.org/10.1016/S0191-8869(00)00171-9

Swannell, S. V., Martin, G. E., Page, A., Hasking, P., \& St. John, N. J. (2014). Prevalence of nonsuicidal self-injury in nonclinical samples: Systematic review, meta-analysis, and meta-regression. Suicide and Life-Threatening Behavior, 44(3), 273-303. doi:10.1111/sltb.12070

Tabachnick, B. G., \& Fidell, L. S. (2007). Using multivariate statistics. Boston, MA: Pearson/Allyn \& Bacon.

Tang, J., Yu, Y., Wu, Y., Du, Y., Ma, Y., Zhu, H., Zhang, P., \& Liu, Z. (2011). Association between non-suicidal self-injuries and suicide attempts in Chinese adolescents and college students: A cross-section study. PLoS ONE, 6(4), e17977. https://doi.org/10.1371/journal.pone.0017977 
Tatnell, R., Kelada, L., Hasking, P., \& Martin, G. (2014). Longitudinal analysis of adolescent NSSI: The role of intrapersonal and interpersonal factors. Journal of Abnormal Child Psychology, 42(6), 885-896. doi:10.1007/s10802-013-9837-6

Turner, B. J., Chapman, A. L., \& Layden, B. K. (2012). Intrapersonal and interpersonal functions of non suicidal self-injury: Associations with emotional and social functioning. Suicide and Life-Threatening Behavior, 42(1), 36-55. doi:0.1111/j.1943-278X.2011.00069.x

Victor, S. E., \& Klonsky, E. D. (2013). Daily emotion in non-suicidal self-injury. Journal of Clinical Psychology, 70(4), 364-375. doi:10.1002/jclp.22037

Voon, D., Hasking, P., \& Martin, G. (2014a). The roles of emotion regulation and ruminative thoughts in non-suicidal self-injury. British Journal of Clinical Psychology, 53(1), 95-113. https://doi.org/10.1111/bjc.12030

Voon, D., Hasking, P., \& Martin, G. (2014b). Change in emotion regulation strategy use and its impact on adolescent nonsuicidal self-injury: A three-year longitudinal analysis using latent growth modeling. Journal of Abnormal Psychology, 123(3), 487-498. http://dx.doi.org/10.1037/a0037024

Zetterqvist, M. (2015). The DSM-5 diagnosis of nonsuicidal self-injury disorder: A review of the empirical literature. Child and Adolescent Psychiatry and Mental Health, 9(1), 31-43. https://doi.org/10.1186/s13034-015-0062-7

Zetterqvist, M., Lundh, L., Dahlström, Ö., \& Svedin, C. G. (2013). Prevalence and function of non-suicidal self-injury (NSSI) in a community sample of adolescents, using suggested DSM-5 criteria for a potential NSSI disorder. Journal of 
Abnormal Child Psychology, 41(5), 759-773. https://doi.org/10.1007/s10802-0139712-5 